\title{
Impacts of climate change under CMIP5 RCP scenarios on the streamflow in the Dinder River and ecosystem habitats in Dinder National Park, Sudan
}

\author{
Amir K. Basheer ${ }^{1,2}$, Haishen Lu ${ }^{1}$, Abubaker Omer ${ }^{1}$, Abubaker B. Ali ${ }^{3}$, and Abdeldime M. S. Abdelgader ${ }^{4,5}$ \\ ${ }^{1}$ State Key Laboratory of Hydrology-Water Resources and Hydraulic Engineering, College of Hydrology and Water \\ Resources, Hohai University, Nanjing, 210098, China \\ ${ }^{2}$ Ministry of Agriculture and Irrigation, River Nile State, P.O. Box 8168, Adamer, 12217, Sudan \\ ${ }^{3}$ Research Center of Fluid Machinery \& Engineering, National Research Center of Pumps, Lab of Water Saving Irrigation, \\ Jiangsu University, Zhenjiang, 212013, China \\ ${ }^{4}$ College of Engineering, Karary University, Khartoum, 12304, Sudan \\ ${ }^{5}$ School of information Science and Eng., Southeast University, Nanjing, 210096, China
}

Correspondence to: Haishen Lu (haishenlu@gmail.com; amir.basheer@yahoo.co.uk)

Received: 19 September 2015 - Published in Hydrol. Earth Syst. Sci. Discuss.: 8 October 2015

Revised: 30 January 2016 - Accepted: 16 March 2016 - Published: 5 April 2016

\begin{abstract}
The fate of seasonal river ecosystem habitats under climate change essentially depends on the changes in annual recharge of the river, which are related to alterations in precipitation and evaporation over the river basin. Therefore, the change in climate conditions is expected to significantly affect hydrological and ecological components, particularly in fragmented ecosystems. This study aims to assess the impacts of climate change on the streamflow in the Dinder River basin (DRB) and to infer its relative possible effects on the Dinder National Park (DNP) ecosystem habitats in Sudan. Four global circulation models (GCMs) from Coupled Model Intercomparison Project Phase 5 and two statistical downscaling approaches combined with a hydrological model (SWAT - the Soil and Water Assessment Tool) were used to project the climate change conditions over the study periods 2020s, 2050s, and 2080s. The results indicated that the climate over the DRB will become warmer and wetter under most scenarios. The projected precipitation variability mainly depends on the selected GCM and downscaling approach. Moreover, the projected streamflow is quite sensitive to rainfall and temperature variation, and will likely increase in this century. In contrast to drought periods during the 1960s, 1970s, and 1980s, the predicted climate change is likely to affect ecosystems in DNP positively and promote the ecological restoration for the habitats of flora and fauna.
\end{abstract}

\section{Introduction}

The climate change over the next century is expected to severely impact water resources; arid and semi-arid areas are particularly more vulnerable to that change and are projected to suffer from water shortage due to precipitation reduction (Tavakoli and De Smedt, 2011; Setegn et al., 2011). Alteration in hydrologic conditions will affect almost every aspect of natural resources and human well-being (Xu, 1999). For instance, ecosystem integrity is influenced either directly or indirectly by climate change and hydrologic variability globally, regionally, and at catchment scale. The responses of ecosystems to alterations in the hydrological process usually include complex interactions of biotic and abiotic processes. Hence, the hydrological variability can highly impact the ecosystem species in a variety of ways, such as the linkage between water availability and metabolic and reproductive processes of that species (Burkett et al., 2005). Among all ecosystems, freshwater aquatic ecosystems seem to have the highest proportion of species threatened with extinction caused by climate change (Millennium Ecosystem Assessment, 2005). The empirical framework of Mantyka-pringle et al. (2012) illustrated that the effects of habitat loss and fragmentation were greatest where the maximum temperature of the warmest month was highest (i.e., effects were greatest in areas with high temperatures). In contrast, the ef- 
fects of habitat loss and fragmentation were lowest in areas where precipitation has increased. In other words, smaller effects occurred in areas where average rainfall has increased over time than in areas where rainfall has decreased. It followed that the maximum temperature and precipitation were the most important variables, with mean temperature change as the third. Thus, both current climate (i.e., maximum temperature) and climate change (i.e., precipitation change) appear to be key determinants of habitat loss and fragmentation effects on terrestrial biodiversity. In some parts of the world, ecosystems are already being affected by climate variability. Furthermore, it is very likely that the magnitude and frequency of ecosystem changes will possibly rapidly increase and continue in the future (Thomas et al., 2004). As the climate conditions have changed in both precipitation and temperature trends over recent decades, the timing of these events has become vulnerable to alteration as well. According to the Gitay et al. (2002) projections, the ecosystem components in the Northern Hemisphere will experience serious alterations in terms of earlier flowering of plants, migration of birds, animal breeding seasons, and emergence of insects. Consequently, under the smallest climatic change scenarios, $18 \%$ of species were found to be committed to extinction, while the largest change scenario projected as many as $35 \%$ of species to be at risk (Thomas et al., 2004). Many studies investigated the impact of the streamflow change on the freshwater ecosystems, which will probably have strong effects on the system components and abiotic characteristics (Poff and Ward, 1989; Poff and Zimmerman, 2010; Döll and Zhang, 2010; Mantyka-pringle et al., 2012). Erwin (2009) concluded that the wetlands will strongly be influenced due to climate alteration and, to overcome all these impacts, assessment of the affect should first be conducted. These assessments should be applied, particularly in semi-arid and arid regions that will be more vulnerable areas (Finlayson et al., 2006).

The climate change in the Upper Blue Nile basin has been addressed by many previous studies using different climate models and techniques (Elshamy et al., 2009; Beyene et al., 2010; Taye et al., 2011; Setegn et al., 2011; Enyew et al., 2014; Gebre et al., 2015). The Dinder River (DR) is one of the largest tributaries of the Blue Nile River and a major water resource in the Dinder National Park (DNP). It seasonally flows down from the western parts of the Ethiopian highlands and flows through the center of the DNP (Abdel Hameed et al., 1997). Seasonality of the DR makes it more sensitive to climate change effects, because it mainly depends on seasonal rainfall, which is expected to be altered in timing and magnitude. Furthermore, ecosystem habitats in the Dinder River basin (DRB) are basically controlled by the river runoff and climate variables such as temperature and precipitation, whereas DNP biodiversity is related to high-flow events of the DR that influence the river channel shape and allow access to other disconnected floodplain habitats, and to lowflow events that limit overall habitat availability and quality.
The ecosystem in the DNP contains a group of islands and wetlands (mayas) consisting of a diverse array of fauna and flora and represent an adequate environment for the most nutritious grasses to the herbivores, especially during the most severe part of the dry season. Thus, relative changes in hydrological processes and climate variables over the DRB directly affect the ecosystem habitats and components in the DNP in general. It should be mentioned that most African countries during the last 5 decades were exposed to drought periods, which started in the 1960s and reached a peak in 1984. Consequently, these drought periods affected every African environmental system, particularly Sudan and Ethiopia (Mattsson and Rapp, 1991; Elagib and Elhag, 2011; Masih et al., 2014).

In order to evaluate the effects of climate change on natural resources and maintain ecosystem integrity at the local and territorial scales, further studies should be conducted within the context of water resource management. One of the best tools for simulating current and future prediction of climate change scenarios is a global circulation model (GCM) (Xu, 1999). However, there is a general consensus among the scientific community that GCM outputs cannot be used directly as input to hydrological models, which often operate on spatial scales smaller than those of GCMs (Wilby et al., 2002). To predict changes in hydrology and water resources, downscaling the outputs of the GCM on the global scale into the inputs of the hydrological model on the regional scale has been widely applied to obtain the hydrological response (Charlton et al., 2006; Steele-Dunne et al., 2008). Statistical downscaling is thus often used to bridge the scale gap in linking GCM outputs with hydrological models because it does not require significant computing resources and can more directly incorporate observations into method (Fowler et al., 2007). The hydrologic models should provide a link between climate changes and water yields through simulation of hydrologic processes within watersheds. The Soil and Water Assessment Tool (SWAT) is one of the widely used models, which has the capability of incorporating the climate change effect for simulation (Ficklin et al., 2010).

To the authors' knowledge, the impact of climate change in the DRB has never been thoroughly investigated, and the hydrological alteration affecting the DNP wetland habitats has not been explicitly explored. This paper is the first step toward reporting the impact of climate change on streamflow in the DR and ecosystem habitats in the DNP. The study area has ecological importance as a national park and biosphere reserve lie in the ecotone between the Sahel and Ethiopian highlands ecoregions. In addition, the change in climate conditions is expected to significantly affect hydrological and ecological components in the DNP fragmented ecosystems. Moreover, projecting the hydroclimatic conditions over the DNP and assessing how ecosystem habitats respond to the changes in these variables would provide benchmark information that can be used to increase the capacity of the water resource management and ecosystem conservation strategies by identifying suitable actions for the future. The objectives 


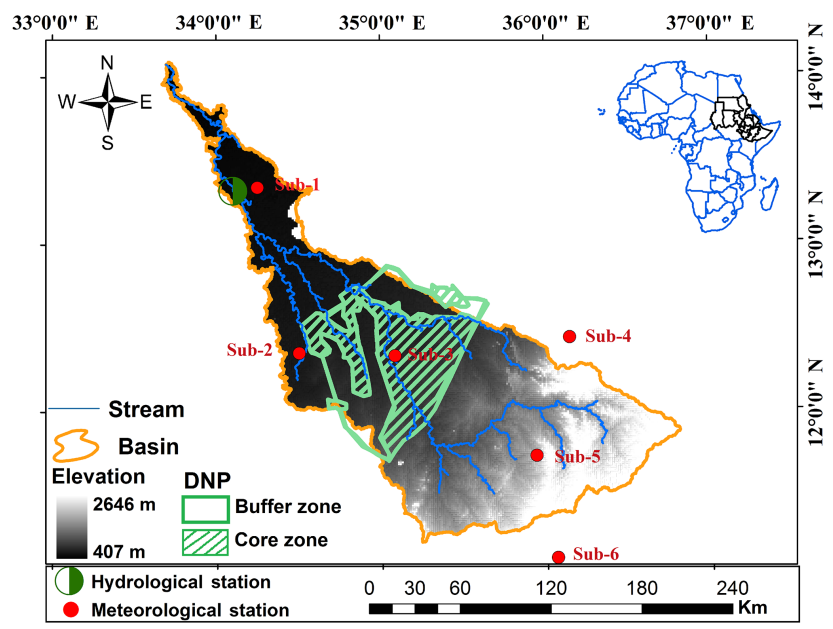

Figure 1. Topography (m) of the DRB based on a $90 \mathrm{~m} \mathrm{DEM}$ and geographic locations of DNP and hydrological and meteorological stations.

of this paper are (1) to assess the effect of climate change on the future streamflow magnitude in the DRB, using the SWAT model coupled with four GCMs under various climate change scenarios and two downscaling approaches, and (2) to investigate the potential impact of climate change on the DNP ecosystem components, in order to provide benchmarked information for the decision-makers to be included in adaptation strategies for water resources and environmentally sustainable development.

The rest of the paper is organized as follows. Section 2 describes the study area and DNP ecosystem components. Section 3 includes a brief description of the SWAT model and two downscaling approaches used to downscale the GCM model outputs, while the Standardized Precipitation Index (SPI) is also highlighted. Section 4 provides the results and discussion of the projected climate variables and streamflow when applying the two downscaling methods, and investigates the effects of theses variables on the ecosystem habitats. Section 5 concludes this work.

Notations: Table 1 presents a list of all symbols, variables, and notations used in this paper.

\section{Study area and Dinder National Park ecosystem}

\subsection{Study area}

The DR is the largest tributary of the Blue Nile in Sudan. It has a seasonal character where it starts surging in June, peaking around the middle of August each year, and in normal conditions ceases flowing in November. The entire basin ranges in elevation from $2646 \mathrm{~m}$ on the Ethiopian Plateau to $407 \mathrm{~m}$ at the northwestern point, where it joins the Blue Nile and its catchment area is about $31422 \mathrm{~km}^{2}$. The DRB geographic coordination is $11^{\circ} 41^{\prime}$ to $13^{\circ} 85^{\prime} \mathrm{N}$ and $34^{\circ}$ to
Table 1. Symbols, variables, and notations.

\begin{tabular}{ll}
\hline Symbols & \\
\hline$a, b$ & Parameter \\
adj & Adjusted \\
$\alpha$ & Shape parameter of Gamma distribution \\
$\beta$ & Scale parameter of Gamma distribution \\
basper & Baseline period (1961-1990) \\
CDF & Cumulative distribution function \\
CF & Change factor method \\
$d$ & Daily \\
$e$ & Euler's number \\
$f$ & Distribution function \\
$F$ & Cumulative distribution function (CDF) \\
$F-1$ & Inverse of CDF \\
fur & Future period (2020s, 2050s, and 2080s) \\
$\Gamma$ & Gamma function \\
$k$ & Number of grid cells \\
$m$ & Month \\
$N$ & Gaussian (normal) distribution \\
$\mu$ & Mean (location parameter of Gaussian distribution) \\
OBS & Observed data (day) \\
$P$ & Precipitation (mm) \\
$p i$ & The weight of each grid cell \\
$\sigma$ & Standard deviation (scale parameter of \\
$\sigma^{2}$ & Gaussian distribution) \\
$T$ & Variance \\
$x$ & Temperature ( ${ }^{\circ}$ C) \\
$X$ & Independent (random) variable \\
$\gamma$ & Percentile \\
$*$ & Gamma distribution \\
\hline & Final bias-corrected \\
\hline & \\
\hline & \\
\hline &
\end{tabular}

$36^{\circ} 20^{\prime} \mathrm{E}$ (Fig. 1). The average annual discharge for the previous 40 years at the $\mathrm{Al}$ Gwisi hydrological station is about 2.2 billion cubic meters (BCM). The main land use and land cover classes in the DRB are agriculture, forest, grass, bush, shrubs, and others (Abdel Hameed, 1983; Abdel Hameed and Eljack, 2003). Land use of the study area has changed over time due to increasing population density and agricultural practices. El Moghraby and Abdu (1985) stated that over the previous decades there had been remarkable population growth due to the successive migration and immigration to the Dinder area. Consequently, the related human activities such as farmland expansion for both traditional and mechanized rain-fed agriculture have been dramatically increased. The clay plains of the DRB are probably the most striking feature of the geomorphology of Sudan (Whiteman, 1971). There are various types of soil in the DRB such as $E u$ tric Cambisols, Chromic Cambisols, Eutric Gleysols, Eutric Regosols, Chromic Vertisols, and Pellic Vertisols. The sandy river bed is left with only a few pools that may hold water after the recession of the river up to the next rainy season (Abdel Hameed, 1983). The annual rainfall amount normally increases gradually from $500 \mathrm{~mm}$ in the northwestern part to 
$1110 \mathrm{~mm}$ in the southeastern part. The DRB drainage system contains of four sub-drainages, namely the Khor Galegu drainage system, which is the biggest tributary of the Dinder River, Khor Masaweek, the eastern bank of the Dinder River, and the western bank of the Dinder River. Each one of these sub-drainages consists of a number of mayas, which are mainly fed by the main DR stream and its tributaries through distinct feeder channels according to the amount of overflow of the river in flood months (Abdel Hameed et al., 1997).

\subsection{Dinder National Park ecosystem}

The DNP is considered to be one of the largest natural reserves in northeastern Africa, and was proclaimed a national park in 1935 following the London Convention (Dasmann, 1972) for the conservation of African flora and fauna. The entire area of the DNP is located inside Sudan between longitudes $34^{\circ} 30^{\prime}$ and $36^{\circ} 00^{\prime} \mathrm{E}$ and latitudes $11^{\circ} 00^{\prime}$ and $13^{\circ} 00^{\prime} \mathrm{N}$, covering an area of $10846 \mathrm{~km}^{2}$ (Fig. 1). The DNP is the only national park north of the 10th parallel, which forms an important ecological zone in the arid and semi-arid SudanoSaharan region. It has a high elevation variation ranging from $800 \mathrm{~m}$ on the Ethiopian Plateau to about $515 \mathrm{~m}$ in the southeastern part and $100 \mathrm{~m}$ in the northeastern part. The park has a unique biodiversity containing a variety of over 250 species of birds and 27 species of large mammals; some of them are listed by the International Union for Conservation of Nature (IUCN) as endangered, vulnerable, or threatened species, in addition to an unknown number of smaller mammals. Therefore, the park is considered to be an adequate habitat for a large number of animals during the dry season and a few numbers when it rains from June through October. The mammalian fauna leave the mayas of the park during the rainy season for the high grounds in the eastern part, in Ethiopia, and return with the onset of the dry season. The mayas are formed by meanders and oxbows along the rivers. They provide dwelling and support for a large number of animal species, such as tiang (Damaliscus korrigum), lion (Panthera leo), elephant (Loxodonta africana, leopard (Panthera par$d u s$ ), wild dog (Lycaon pictus), red-fronted gazelle (Gazella rufifrons), greater kudu (Tragelaphus strepsicerus), Nubian giraffe (Giraffa camelopardalis), black-backed jackal (Conis mesomelas), Arabian bustard, and greater bustard. There are also numerous hides of insects, which serve a vital function in recycling of the organic compounds (Abdel Hameed and Eljack, 2003).

\section{Methods and data}

\subsection{Hydrological model}

Several hydrological models have been developed for application in hydrologic systems and water resource management. One such model utilized in this study is SWAT, which is a distributed watershed-scale hydrological model devel- oped by the United States Department of Agriculture (Arnold et al., 1998). SWAT is a continuous, i.e., a long-term yield model, distributed-parameter hydrological model designed to predict the impact of land management practices on the hydrology and sediment and contaminant transport in agricultural watersheds (Arnold et al., 1998). SWAT sub-divides a watershed into sub-basins connected by a stream network, and further delineates hydrologic response units (HRUs) consisting of unique combinations of land cover and soils within each sub-basin. The model assumes that there are no interactions among HRUs, and these HRUs are virtually located within each sub-basin. HRUs delineation minimizes the computational efforts of simulations by lumping similar soil and land use areas into a single unit (Neitsch et al., 2002). The SWAT model is widely documented in much of the literature (e.g., Neitsch et al., 2005a, b). SWAT provides two methods for estimating surface runoff, which are the SCS curve number and the Green-Ampt infiltration method. The model calculates the peak runoff rate with a modified rational method (Chow et al., 1988). In this study, SWAT was used to simulate streamflow in the DRB. In Arc-SWAT, the basin was divided into 38 sub-basins, which were further sub-divided into 116 HRUs based on soil, land cover, and slope attributes. The surface water runoff volume was estimated using the SCS curve number method. SWAT was calibrated for the whole basin during the period 1989-1993 based on daily and monthly streamflow at the Al Gwisi hydrological station and the model inputs. Then, the model was further validated over the period 1995-1999. The most sensitive parameters were identified with the built-in sensitivity analysis tool in SWAT. We choose the 10 most sensitive parameters $(\mathrm{Cn} 2$, Alpha_BF, GW_DELAY, Ch_K2, Esco, GWQMN, Ch_N2, GW_REVAP, EPCO, and ALPHA_BNK) based on the ranking of sensitivity analysis. Those sensitive parameters were automatically calibrated using the Sequential Uncertainty Fitting (SUFI-2) algorithm (Abbaspour et al., 2007). The Nash-Sutcliffe efficiency coefficient (NS) and the correlation coefficient $\left(R^{2}\right)$ were used to assess the predictive power of SWAT in this study.

\subsection{Global circulation model selection}

To investigate the local impact of climate change, researchers need to select GCMs able to capture the present-day climate of the study area. Therefore, a comparison between the intra-annual variability of monthly statistics of rainfall (i.e., mean, variance and correlation) and temperature provided by the four GCMs and actual observations is conducted. As the World Meteorological Organization (WMO) recommended the use of the period 1961-1990 as a representative period of the present-day climate, since it incorporates some of the natural alterations of the climate, containing both dry (1970s) and wet (1980s) periods (Wigley and Jones, 1987), this period was selected as a baseline. 


\subsection{Statistical downscaling of temperature and rainfall time series}

The GCM output resolution is too coarse for a regional impact assessment study; therefore, downscaling must be performed before applying GCM outputs to the SWAT model (Dessu and Melesse, 2013). Both change factor (CF) and quantile mapping $(\mathrm{QM})$ downscaling methods were used to downscale GCM outputs.

\subsubsection{Change factor downscaling method $(\mathrm{CF})$}

In general, the CF method (Hay et al., 2000; Diaz-Nieto and Wilby, 2005) is an ordinary bias correction method. The CF method is often used to exclude or minimize the bias between observations and the model outputs. The CF procedures rely on modifying the daily time step series of the climate variables such as precipitation and temperature for prediction periods (2020s, 2050s, and 2080s) by adding the monthly mean changes in GCM outputs. The adjusted formulas that are used to modify daily temperature and precipitation are expressed in Eqs. (1) and (2):

$$
\begin{aligned}
& T_{- \text {adj;fur } \mathrm{d}}=T_{-\mathrm{OBS} ; \mathrm{d}} \\
& \quad+\sum_{i=1}^{k} p i\left(\bar{T}_{\mathrm{GCM} ; \text { fur } ; \mathrm{m}}-\bar{T}_{\mathrm{GCM} ; \text { basper } ; \mathrm{m})},\right. \\
& P_{\text {adj;fur; } \mathrm{d}}=P_{\mathrm{OBS} ; \mathrm{d}} \\
& \quad \times \sum_{i=1}^{k} p i\left(\bar{P}_{\mathrm{GCM} ; \text { fur } ; \mathrm{m}} / \bar{P}_{\mathrm{GCM} ; \text { basper } ; \mathrm{m}}\right)
\end{aligned}
$$

where $T_{\text {adj; fur; }} \mathrm{d}$ is the adjusted daily temperature ( $T_{\max }$ and $T_{\min }$ ) for the future years, $T_{\mathrm{OBS} ; \mathrm{d}}$ is the observed daily temperature for the baseline years, $T_{\mathrm{GCM}}$; fur; $\mathrm{m}$ is the monthly mean temperature of the GCM outputs for the future years, $T_{\mathrm{GCM}}$; basper; $\mathrm{m}$ is the monthly mean temperature of the GCM outputs for the baseline years, $p i$ is the weight of each grid cell, and $k$ is the number of grid cells.

\subsubsection{Quantile mapping downscaling method (QM)}

The QM is an emerging downscaling approach that is utilized to remove bias of observed and simulated rainfall using cumulative distribution functions (CDF). The QM method basically replaces the simulated (GCMs) rainfall/temperature value with the observed value that has the same nonexceedance probability. It shifts the occurrence distributions of precipitation/temperature by creating a transfer function (Sennikovs and Bethers, 2009; Teutschbein and Seibert, 2012). The recommended function for distributions of precipitation events is the Gamma distribution (Thom, 1958) as shown in Eq. (3).

$$
f \gamma(X / \alpha, \beta)=x^{\alpha-1} \cdot \frac{1}{\beta^{\alpha} \cdot \Gamma(\alpha)} \cdot e^{\frac{-x}{\beta}} ; x \geq 0 ; \alpha, \beta>0,
$$

where $\alpha$ is the shape parameter of the Gamma distribution, $\beta$ is the scale parameter of the Gamma distribution, $f$ is the distribution function, e is Euler's number, $\Gamma$ is the Gamma function, $\gamma$ is the Gamma distribution, $X$ is the percentile, and $x$ is an independent (random) variable.

For temperature time series, the Gaussian distribution with location parameter $\mu$ and scale parameter $\sigma$ (Eq. 4) is usually assumed to fit best (Thom, 1958; Cramér, 1999):

$$
f N\left(X \mid \mu, \sigma^{2}\right)=x^{\alpha-1} \frac{1}{\sigma \cdot \sqrt{2 \pi}} \cdot e^{\frac{-(x-\mu)^{2}}{2 \sigma^{2}}} ; x \in R .
$$

The scale parameter $\sigma$ determines the standard deviation, i.e., how much the range of the Gaussian distribution is stretched or compressed. A smaller value for $\sigma$ results in a more compressed distribution with lower probabilities of extreme values. By contrast, a larger value for $\sigma$ indicates a stretched shape with higher probabilities of extreme values. The location parameter $\mu$ directly controls the mean and, therefore, the location of the distribution.

In this paper, we used an advanced version of the QM approach developed recently by Willems et al. (2012). The CDFs were set up on a daily basis for observed (1961-1990) and GCM-simulated rainfall for the baseline period (19611990). Then the GCM output value of a certain day was looked up based on the constructed CDF relative to the GCM simulations with their corresponding cumulative probability (Fig. 2). Subsequently, the same cumulative probability of the precipitation value was located in the empirical CDF of observations. Next, this value was used to adjust the GCM baseline simulation (1961-1990). The Gamma CDF $(F \gamma)$ and its inverse $\left(F \gamma^{-1}\right)$ can elucidate this procedure mathematically as follows:

$$
\begin{aligned}
& P_{\text {basper }}^{*}(d)=F_{\gamma}^{-1}\left(F_{\gamma}\left(P_{\text {basper }}(d) \mid \alpha_{\text {basper,d }}, \beta_{\text {basper }, \mathrm{d}}\right) \mid\right. \\
& \left.\quad \alpha_{\text {obs,d }} \beta_{\text {obs,d }}\right), \\
& P_{\text {fut }}^{*}(d)=F_{\gamma}^{-1}\left(F_{\gamma}\left(P_{\text {fut }}(d) \mid \alpha_{\text {fut }, \mathrm{d},} \beta_{\text {fut }, \mathrm{d}}\right) \mid \alpha_{\text {obs }, \mathrm{d}}, \beta_{\text {obs }, \mathrm{d}}\right),
\end{aligned}
$$

where $P_{\text {basper }}^{*}$ is precipitation bias corrected for the base period of GCM, $P_{\text {fut }}^{*}$ is precipitation bias corrected for the future period of GCM, $F$ is a cumulative distribution function (CDF), $F_{\gamma}^{-1}$ is the inverse of (CDF), and $\gamma$ is the Gamma distribution (Willems et al., 2012).

With regard to temperature, the same procedure can be expressed in terms of the Gaussian $\operatorname{CDF}\left(F_{\mathrm{N}}\right)$ and its inverse $\left(F_{\mathrm{N}}^{-1}\right)$ as

$$
\begin{aligned}
& T_{\text {basper }}^{*}(d)=\mathrm{F}_{\mathrm{N}}^{-1}\left(F_{\mathrm{N}}\left(T_{\text {basper }}(d) \mid \mu_{\text {basper }, \mathrm{d}}, \sigma_{\text {basper }, \mathrm{d}}^{2}\right) \mid\right. \\
& \left.\quad \mu_{\mathrm{obs}, \mathrm{d}}, \sigma_{\mathrm{obs}, \mathrm{d}}^{2}\right), \\
& T_{\text {fut }}^{*}(d)=F_{\mathrm{N}}^{-1}\left(F_{\mathrm{N}}\left(T_{\text {fut }}(d) \mid \mu_{\text {fut }, \mathrm{d}}, \sigma_{\text {fut }, \mathrm{d}}^{2}\right) \mid \mu_{\mathrm{obs}, \mathrm{d}}, \sigma_{\mathrm{obs}, \mathrm{d}}^{2}\right),
\end{aligned}
$$

where $T_{\text {basper }}^{*}$ is temperature bias corrected for the base period of GCM, $T_{\text {fut }}^{*}$ is temperature bias corrected for the future period of GCM, $T$ is temperature, $\mu$ is the mean (location parameter of the Gaussian distribution), $\sigma$ is the standard deviation (scale parameter of the Gaussian distribution), and $\sigma^{2}$ is variance (Teutschbein and Seibert, 2012). 

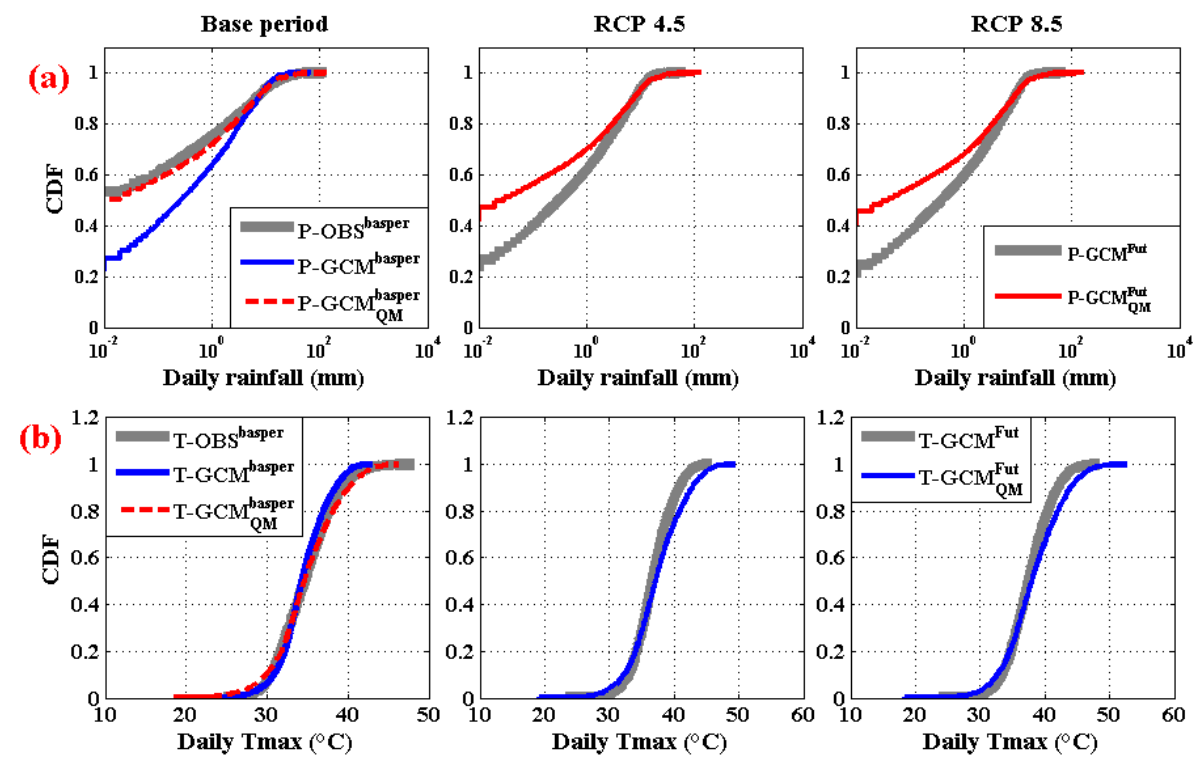

Figure 2. (a) Comparison between the empirical cumulative density function of the observed rainfall data and the one provided by the MIROC-ESM model, before (dashed line) and after (solid line) the application of the QM method: the Base period and future climate (RCP4.5 and RCP8.5) over the study area. (b) Same comparison done for $T_{\max }$ by using a Gaussian distribution for the MPI-ESM-LR model.

The stationarity assumption, i.e., that the same correction algorithm applies to both current and future climate conditions, is considered the main drawback of the QM method. Furthermore, the difference between the two downscaling approaches is that the CF method can obtain daily future precipitation time series by adding the average monthly changes of GCM outputs to the observed data. Conversely, the QM approach directly adjusted the daily time series generated by the GCM based on linkage of GCM outputs and observed data in the baseline period (Camici et al., 2013).

\subsection{Dryness and wetness patterns over the DRB}

Monitoring the drought phenomena and quantifying the wet/dry conditions of the climate are characterized by the use of various drought indices (Kallis, 2008; Mishra and Singh, 2010; Elagib and Elhag, 2011; Elagib, 2013). The Standardized Precipitation Index (McKee et al., 1993) is most widely used to estimate drought indices. The SPI quantifies precipitation deficiency at different timescales based on the probability of recording a given quantity of precipitation, and the probabilities are standardized in such a way that an index of zero indicates the median precipitation amount. The index is positive for wet conditions and negative for drought. Although SPI-1, SPI-3, and SPI-6 captured historical drought events, SPI-12 is usually tied to streamflows and reservoir levels at longer timescales. The SPI at 12 months is an evaluation of the precipitation for 12 consecutive months compared with that recorded in the same 12 consecutive months in all previous years of available data. Since these timescales are the cumulative results of shorter periods that may be above or below normal conditions, the longer SPIs tend to gravitate toward zero unless a distinctive wet or dry trend is taking place. Moreover, the long-term droughts of 12 months may represent hydrological droughts (Svoboda et al., 2012). Therefore, in this study, SPI at a 12-month timescale was computed using observed monthly precipitation at six stations from 1961 to 1990 to represent the historical dryness and wetness events over the DRB. For the future, the 90-year SPI-12 series of the rainfall over the DRB was computed for each future precipitation scenario and compared with those from the baseline precipitation. The Gamma distribution was chosen in this study for description of the precipitation time series according to the McKee et al. (1993) recommendation.

\subsection{Data}

The topographic data used in this study were generated from a $90 \mathrm{~m}$ resolution DEM (digital evaluation model) (Fig. 1) obtained from http://gdex.cr.usgs.gov/gdex/ and processed within Arc-SWAT to provide local elevation, slope, and flow direction. The soil map $(1000 \mathrm{~m} \times 1000 \mathrm{~m}$ resolution $)$ for the study area was extracted from the digital soil map of the world (FAO) (http://www.fao.org/geonetwork/srv/en/ main.home) and the African soil map (http://africasoils.net/). The land use map $(1 \mathrm{~km})$ in this study was obtained from the Land Cover Institute (LCI) (http://landcover.usgs.gov/). Daily meteorological data such as temperature and precipitation were collected from the Ministry of Water Resources and Electricity and other different sources for the period 
Table 2. Information of the climate models.

\begin{tabular}{lll}
\hline Model name & Model center & Grid resolution \\
\hline CCSM4 & The National Center for Atmospheric Research, USA & $0.9424^{\circ} \times 1.25^{\circ}$ \\
MIROC-ESM & JAMSTEC, AORI, and NIES, Japan & $2.7906^{\circ} \times 2.8125^{\circ}$ \\
MPI-ESM-LR & Max Planck Institute for Meteorology, Hamburg, Germany & $1.8653^{\circ} \times 1.875^{\circ}$ \\
MPI-ESM-MR & Max Planck Institute for Meteorology, Hamburg, Germany & $1.865^{\circ} \times 1.875^{\circ}$ \\
\hline
\end{tabular}
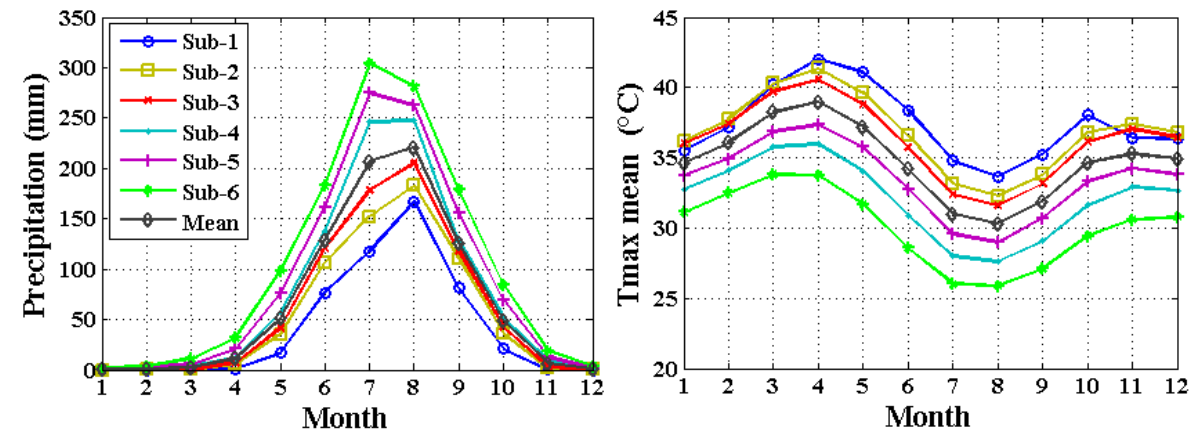

Figure 3. The mean monthly rainfall and $T_{\max }$ regimes of all the climate stations used in this study for the period of $1961-1990$.

1961 to 2008. The meteorological data were interpolated using high-intensity stations distributed over the Blue Nile region. Daily records of the river discharge at the Al Gwisi hydrological station obtained from the Ministry of Water Resources and Electricity of Sudan were used to calibrate and validate SWAT. Four GCMs have been selected for future climate change projections over the DRB. Table 2 gives an overview of GCMs. The selection of the GCM model was based on other studies related to the impact of climate change on the Upper Blue Nile watershed on the Ethiopian Plateau. The MPI-ESM-LR and MPI-ESM-MR models as a recently amended version of the ECHAM5 model are recognized as being capable of reproducing the precipitation and temperature pattern on the Ethiopian Plateau (Beyene et al., 2010; Taye et al., 2011; Enyew et al., 2014; Gebre et al., 2015). The MIROC-ESM and CCSM4 (Jury, 2015) models similarly have been selected (Elshamy et al., 2009; Beyene et al., 2010; Setegn et al., 2011). However, for CCSM4, there is a clear difference in rainfall trend (base period) in some months. The RCP4.5 is considered to be a moderate mitigation scenario, while RCP8.5 is the higher stabilization pathway, which would provide a wider range of radiative forcing across the RCP extensions. Therefore, RCP4.5 and RCP8.5 might be suitable for studying the impact of climate change over the DRB and inferring the possible response of the DNP ecosystem's habitats, because they have the ability to consider the moderate and extreme scenarios required for planning a better ecosystem restoration management strategy. The daily precipitation, $T_{\max }$ and $T_{\min }$ from 1961 to 2095, was extracted from grid cells covering the DRB. The period from 1961 to 1990 was defined as the baseline period (denoted by the 1980s), while the future periods that are covered by this study are 2006-2035, 2036-2065, and 20662095 (denoted by the 2020s, 2050s, and 2080s, respectively), except precipitation for the CCSM4 model under the RCP8.5 scenario (2066-2093).

\subsection{Climatic condition of the study area}

The precipitation and temperature vary spatially and temporally over the DRB. The annual precipitation increases by about $30 \mathrm{~mm}$ every $10 \mathrm{~km}$ from the northwest to the southeast (Ethiopian Plateau), while the temperature decreases with the rainfall increase. Figure 3 displays the mean monthly rainfall and temperature regimes of all the climate stations in the DRB for the period of 1961-1990. It is clear from Fig. 3 and Table 3 that the DRB is hotter in the northwestern part, with a mean $T_{\max }$ of $37.39^{\circ} \mathrm{C}$, than in the southeastern part $\left(30.09^{\circ} \mathrm{C}\right)$. The whole basin has a mean $T_{\max }$ of $34.77^{\circ} \mathrm{C}$. The hottest months are April and May in the whole basin, while July and August are the coldest ones. The annual rainfall spatial distribution varies conversely with the $T_{\max }$; Sub1 (with an annual rainfall of $480.92 \mathrm{~mm}$ ) and Sub-6 (with an annual rainfall of $1201.12 \mathrm{~mm}$ ) are the lowest and heaviest stations, respectively.

\section{Results and discussions}

\subsection{Calibration and validation for the SWAT model}

Firstly, SWAT was calibrated for the whole basin during the period 1989-1993 based on daily and monthly streamflow at the $\mathrm{Al}$ Gwisi hydrological station and the model inputs. Then, the model was further validated over the period 1995- 


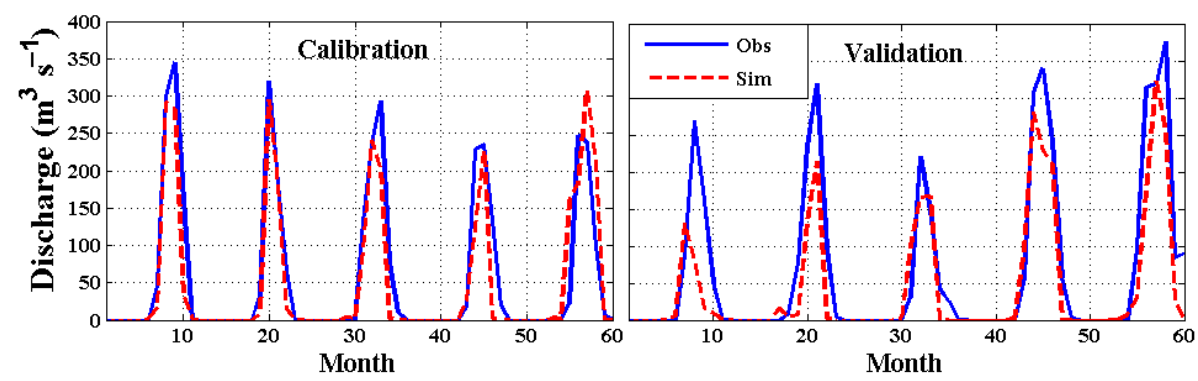

Figure 4. SWAT simulated and observed monthly streamflow in Al Gwisi gauge during the calibration period (1989-1993) (lift panel) and validation period (1995-1999) (right panel); Obs indicates the observed flow and Sim indicates the simulated flow.

Table 3. Statistics of climate stations for the period of 1961-1990 in the DRB.

\begin{tabular}{lllll}
\hline Sub-station & Elevation & Annual rainfall $(\mathrm{mm})$ & Mean $T_{\max }\left({ }^{\circ} \mathrm{C}\right)$ & Mean $T_{\min }\left({ }^{\circ} \mathrm{C}\right)$ \\
\hline Sub-1 & 425 & 480.92 & 37.39 & 21.49 \\
Sub-2 & 442 & 630.16 & 36.81 & 21.53 \\
Sub-3 & 487 & 716.34 & 36.23 & 18.84 \\
Sub-4 & 714 & 894.04 & 32.09 & 21.19 \\
Sub-5 & 824 & 1042.6 & 33.49 & 17.73 \\
Sub-6 & 886 & 1201.12 & 30.09 & 16.15 \\
\hline
\end{tabular}

Table 4. Calibration (1989-1993) and validation (1995-1999) for the SWAT model.

\begin{tabular}{lcccc}
\hline \multirow{2}{*}{ Period } & \multicolumn{2}{c}{ Monthly } & \multicolumn{2}{c}{ Daily } \\
\cline { 2 - 5 } & NS & $R^{2}$ & NS & $R^{2}$ \\
\hline Calibration (1989-1993) & 0.81 & 0.83 & 0.62 & 0.63 \\
Validation (1995-1999) & 0.76 & 0.82 & 0.51 & 0.56 \\
\hline
\end{tabular}

1999. Results showed that SWAT could successfully simulate reasonable daily and monthly streamflow in the DRB as shown in Fig. 4. The coefficient of determination $\left(R^{2}\right)$ and the Nash-Sutcliffe coefficient of efficiency values (NSE) were 0.83 and 0.81 for the calibration period and 0.82 and 0.76 during the validation period, respectively. For the daily simulation, $R^{2}$ and NSE values were 0.63 and 0.61 for the calibration period and 0.56 and 0.51 for the validation period as listed in Table 4.

\subsection{Global circulation model analysis}

The annual variability of the monthly mean, variance, and autocorrelation of daily precipitation for the four GCM outputs, and the observed data averaged for the period 1961-1990, is given in Fig. 5. For the MPI-ESM-LR and MPI-ESM-MR models, the annual variability of the monthly mean precipitation data is completely in order, corresponding to the observed data. For the MIROC-ESM and CCSM4 models, most months were quite good, while other months (April and June) showed a clear difference. Furthermore, the MPI-ESM-LR and MPI-ESM-MR models have a general tendency to underestimate the monthly variance throughout the year, while other models have high variance in some months. For the autocorrelation, the four models have opposite behavior. Figure 6 illustrates the comparison between the four GCM outputs and the observed data for the $T_{\max }$ and $T_{\min }$ data in terms of monthly mean and variance. The four GCMs are capable of reproducing the observed mean $T_{\max }$ and $T_{\min }$ values with small biases. With regard to the variance, the MIROC-ESM and CCSM4 showed clear differences in some months, while the MPI-ESM-LR and MPI-ESM-MR presented a slight variance.

In general, the results of the statistical tests of GCM performance to simulate historical records of climatic variables show better simulation results for temperature than for rainfall. The poor result of rainfall simulation is due to GCM failure to simulate the seasonal migration of the Inter-Tropical Convergence Zone (ITCZ) in these equatorial regions (Wu et al., 2003). It is also attributed to the complex climate system and topography of the Blue Nile basin. For instance, the summer (JJA) rainfall in the catchment is influenced by monsoon activity (Beyene et al., 2010), which might not be accurately considered by the GCMs (Taye et al., 2011).

Taking into account these results and the uncertainties estimated by GCMs, the four models have been selected for representing the actual climate over the DRB. This selection is also supported by the ability of these models to reproduce the mean annual precipitation, which is considered to be the main factor leading to huge impact on the DRB and DNP. 

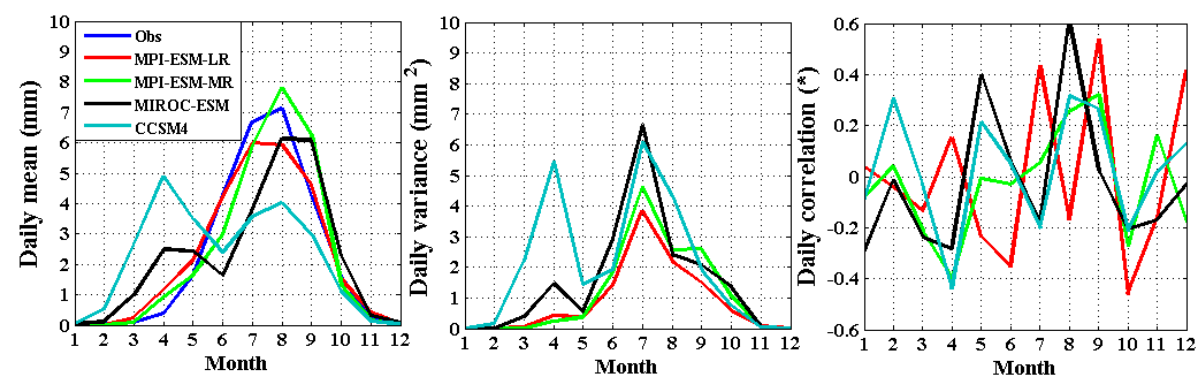

Figure 5. Comparison between the statistical properties of the observed daily precipitation data for the period 1961-1990 and the four GCM outputs.
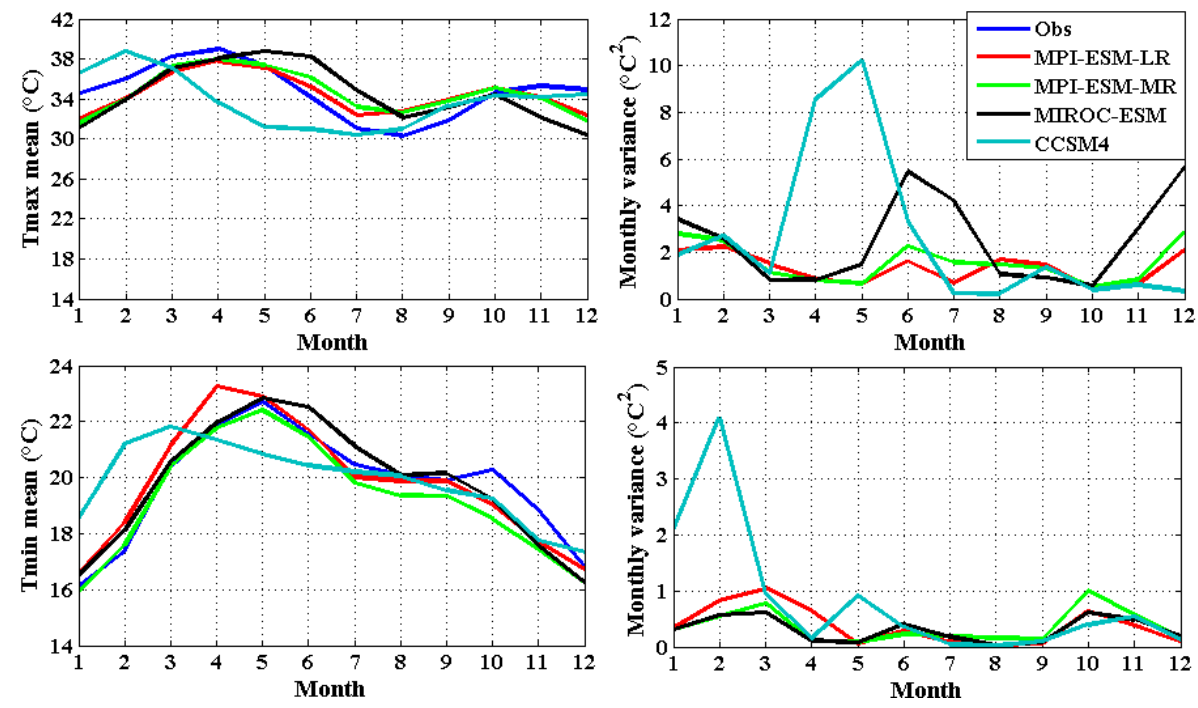

Figure 6. Comparison between the statistical properties of the observed temperature (1961-1990) and the four GCM outputs; the $T_{\text {max }}$ (upper panel) and $T_{\min }$ (lower panel) data.

\subsection{Statistical downscaling of GCM outputs}

Figures 7 and 8 show the results for the downscaling of the annual average $T_{\max }$ and $T_{\min }$ time series provided by the four models through the $\mathrm{CF}$ and $\mathrm{QM}$ methods. In the base period comparison between the observed data $(T-$ OBS $^{\text {basper }}$ ) and the results provided by the GCMs before $\left(T-\mathrm{GCM}^{\text {basper }}\right)$ and after $\left(T-\mathrm{GCM}_{\mathrm{QM}}^{\text {basper }}\right)$, the application of the QM approach is depicted, while in the future periods (RCP4.5 and RCP8.5) the GCM outputs for the future $\left(T-\mathrm{GCM}^{\text {fur }}\right)$ and the results provided by the application of the $\mathrm{QM}\left(T-\mathrm{GCM}_{\mathrm{QM}}^{\mathrm{fut}}\right)$ and $\mathrm{CF}$ methods $\left(T-\mathrm{OBS}_{\mathrm{CF}}^{\text {fut }}\right)$ are compared. As is shown in the figures, there is no such big difference between temperature predicted by the MPI-ESM-L, MPI-ESM-MR, and MIROC-ESM models when the CF and QM approaches were used, corresponding to their simulated output, whilst the CCSM4 gave a remarkable difference. Figure $9 \mathrm{a}$ displays the relationship between the mean daily $T_{\max }$ projected by the two downscaling approaches and GCM outputs for the study periods. There is a slight difference be- tween $T_{\max }$ obtained by GCM outputs and that projected by MPI-ESM-LR, MPI-ESM-MR, and MIROC-ESM using the two downscaling methods, while with the CCSM4 model, the $\mathrm{CF}$ method demonstrated a clear difference in some months. Moreover, the correlation between the mean daily $T_{\max }$ projected by the CF, QM, and baseline period corresponding to the GCM outputs is illustrated in Fig. 9b. It can be seen that the QM is highly correlated with GCM outputs in contrast to the $\mathrm{CF}$ method. Figure 9c demonstrates the variance of the mean daily $T_{\max }$ generated by the CF and QM relative to the simulations of the four GCMs. The MPI-ESM-LR, MPIESM-MR, and MIROC-ESM models showed slight variance when the CF and QM methods were applied. The CCSM4 model under the $\mathrm{CF}$ approach showed significant variance in some months compared with the QM method. For the mean daily $T_{\min }$ results, it is found that the two downscaling methods obtain the same trend of $T_{\max }$ in the mean, correlation, and variance values for the four GCMs.

For precipitation, referring to Fig. 10 in the base period, the comparison between the observed data of annual av- 

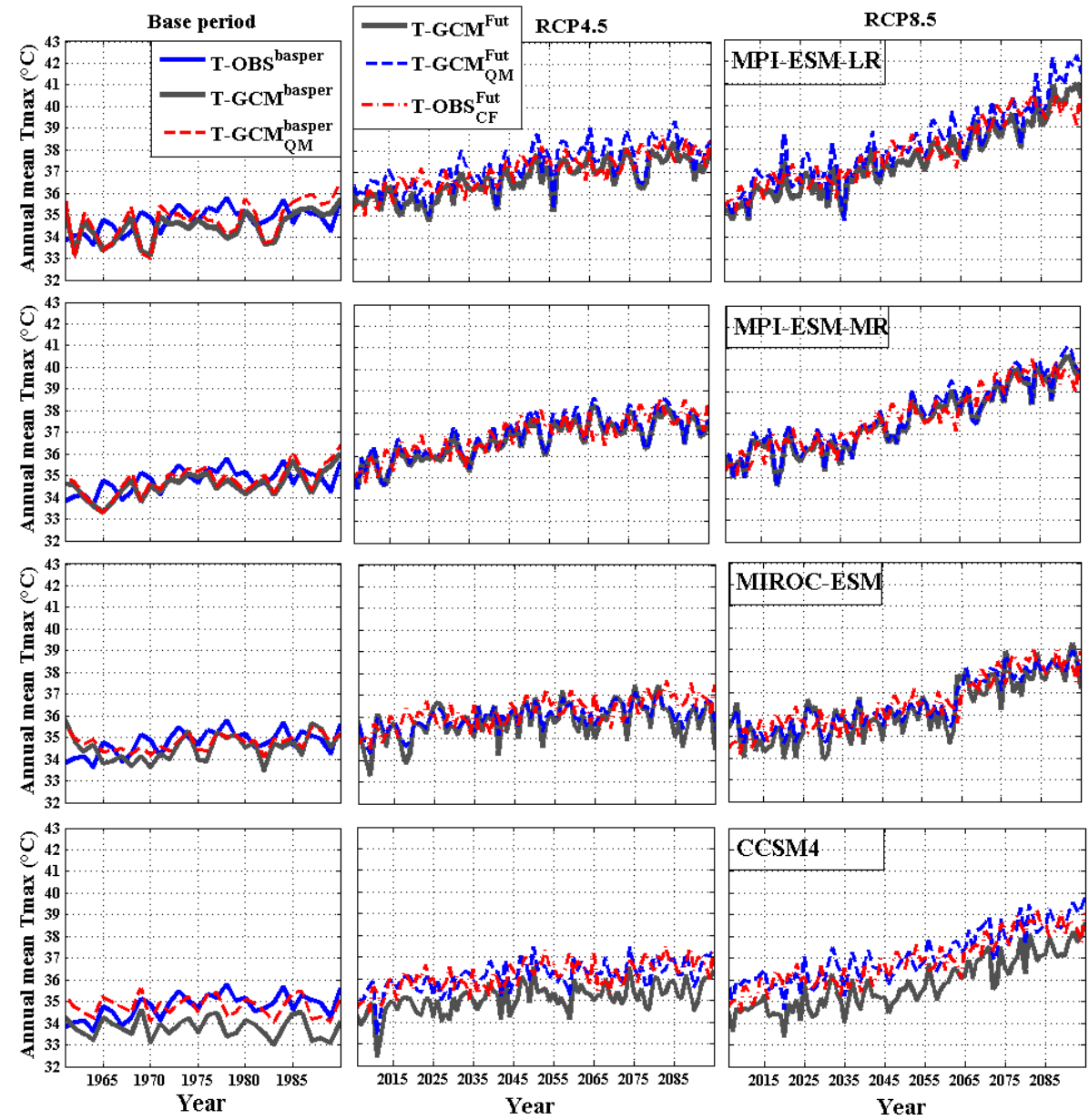

Figure 7. Comparison between the annual $T_{\max }$ data observed for the DRB and the results provided by the four GCM models, before (grey line) and after (dashed line) applying the QM approach (the CF method is added for the future climate): the Base period; and future climate (for RCP4.5 and RCP8.5).

erage rainfall time series $\left(P-\mathrm{OBS}^{\text {basper }}\right)$ and the results provided by the GCMs before $\left(P-\mathrm{GCM}^{\text {basper }}\right)$ and after $\left(P-\mathrm{GCM}_{\mathrm{QM}}^{\text {basper }}\right)$, the application of the $\mathrm{QM}$ approach is depicted, whereas the future periods (RCP4.5 and RCP8.5) show the annual average rainfall time series of the GCM outputs before $\left(P-\mathrm{GCM}^{\text {fur }}\right)$ and after $\left(P-\mathrm{GCM}_{\mathrm{QM}}^{\text {fur }}\right)$ applying the $\mathrm{QM}$ method and future data obtained by the application of the CF method $\left(P-\mathrm{OBS}_{\mathrm{CF}}^{\text {fut }}\right)$. There is a slight difference between the mean annual rainfall projected by the QM approach and GCM outputs, while the CF method shows remarkable dissimilarity. For statistical analysis, the relationship between the mean daily rainfall projected by the two downscaling approaches and GCM outputs for the study periods is shown in Fig. 11a. The MPI-ESM-LR and MPI-ESMMR models showed a slight difference in mean daily rainfall when the QM and CF are applied, corresponding to their simulated outputs, while the MIROC-ESM and CCSM4 models observed a significant difference when the CF is used. Nevertheless, the MIROC-ESM and CCSM4 models showed an insignificant difference when the QM approach is employed. Figure $11 \mathrm{~b}$ displays the correlation between the mean daily rainfalls projected using the $\mathrm{CF}$ and $\mathrm{QM}$ approaches and the observed data corresponding to the GCM outputs. The QM method showed a high correlation with GCM outputs compared with the $\mathrm{CF}$ method. Figure $11 \mathrm{c}$ demonstrates the variance of the mean daily rainfall generated by the $\mathrm{CF}$ and $\mathrm{QM}$ methods relative to the simulations of the four GCMs. The QM method showed slight variance when it was applied for four models. For the CF approach, the MPI-ESM-LR and MPI-ESM-MR observed slight variance. Conversely, there is a significant variance in mean daily rainfall provided by MIROC-ESM and CCSM4. 

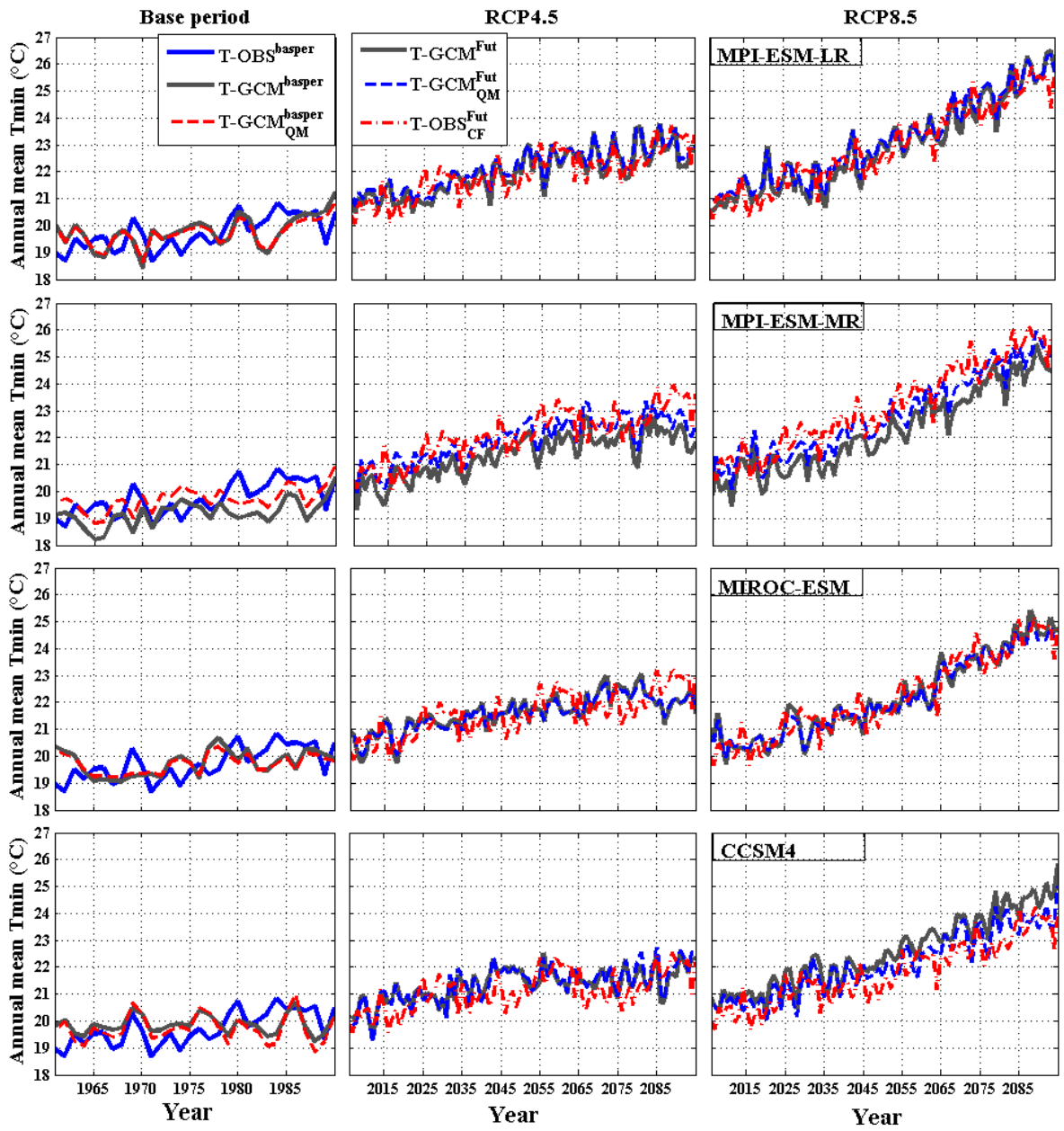

Figure 8. As in Fig. 7 but for the $T_{\min }$.

\subsection{Historical climate impact}

\subsubsection{Historical dryness and wetness patterns over the DRB}

Figure 12 shows the time series of the SPI on annual bases over the DRB. The SPIs for the 1960s were a mixture of below- and above-normal values, but the first half of the decade had very wet $(1.72)$ and moderately dry $(-1.4)$ conditions in 1963/1964 and 1964/1965, respectively. The 1970s period saw wet conditions in the first half of the decade, with some years being extremely (2.42) in 1973/1974 and moderately wet (1.46) in 1974/1975, while the latter were nearnormal records. The 1980s had persistent dry conditions continue until the end of the decade. This period was the driest throughout the study period (moderately and severely dry). The 1981/1982 season was revealed to be the worst single drought, with severely dry conditions $(-1.62)$. Moreover, both the 1980/1981 and 1987/1988 seasons were exceptionally near normal, while the $1988 / 1989$ season was moderately wet.

\subsubsection{Impact of climate change during the drought periods (1960s, 1970s, and 1980s) on the streamflow and ecosystem}

To the best of our knowledge, the DNP ecosystem has three major components, namely woodlands (A. Seyal-Balanites), river streams, and the mayas (wetlands). Moreover, the DNP ecosystem provides sustainable habitats for many species of flora and fauna, in which they live or spend a part of essential key stages of their annual life cycles. Specifically, river streams and the mayas that offer sustainable refuge and protection for the living organisms after the flood season are considered by them to be a valuable store for that reactive link to continue their flora and fauna existence until the next flood start and to recharge the pools and mayas (Hakim et al., 1978; Abdel Hameed and Eljack, 2003). The climate change had pronounced effects on the streamflow of the DR and the mayas by changing the precipitation and occurrence of drought waves. The huge impact of the drought intervals caused significant variability in the water level in the DR and the mayas during the flood season. These changes could be 

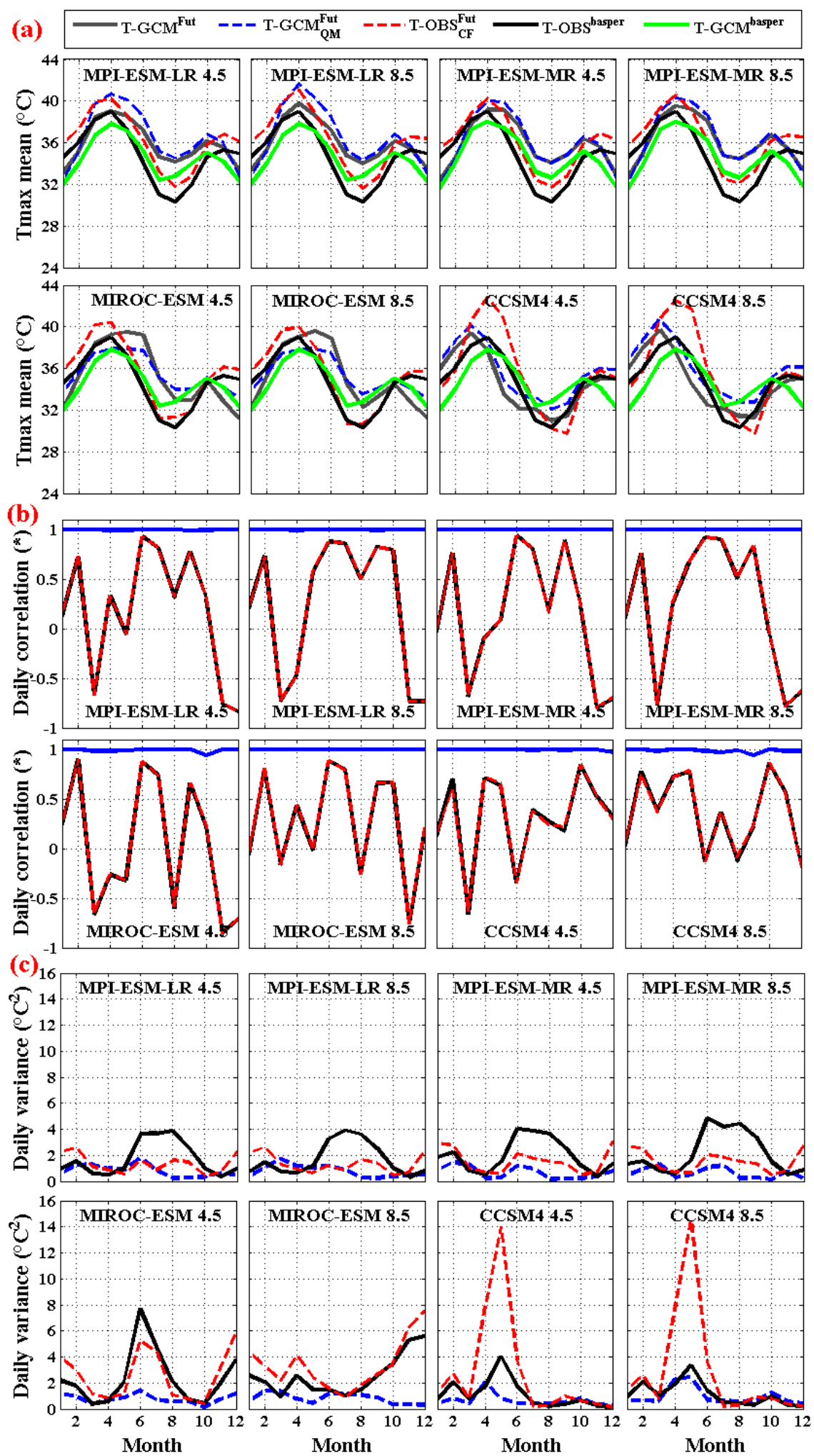

Figure 9. The MPI-ESM-LR, MPI-ESM-MR, MIROC-ESM, and CCSM4 model results over the DRB. Comparison at monthly level between the statistical properties of the GCM output $\left(T_{\max }\right)$ data and its downscaled data using the $\mathrm{CF}\left(P-\mathrm{OBS}_{\mathrm{CF}}^{\mathrm{fut}}\right)$ and $\mathrm{QM}\left(P-\mathrm{GCM}_{\mathrm{QM}}^{\mathrm{fut}}\right)$ approaches. For more explanation, the observed data for the baseline period $\left(P-\right.$ OBS $\left.^{\text {basper }}\right)$ are also shown. 


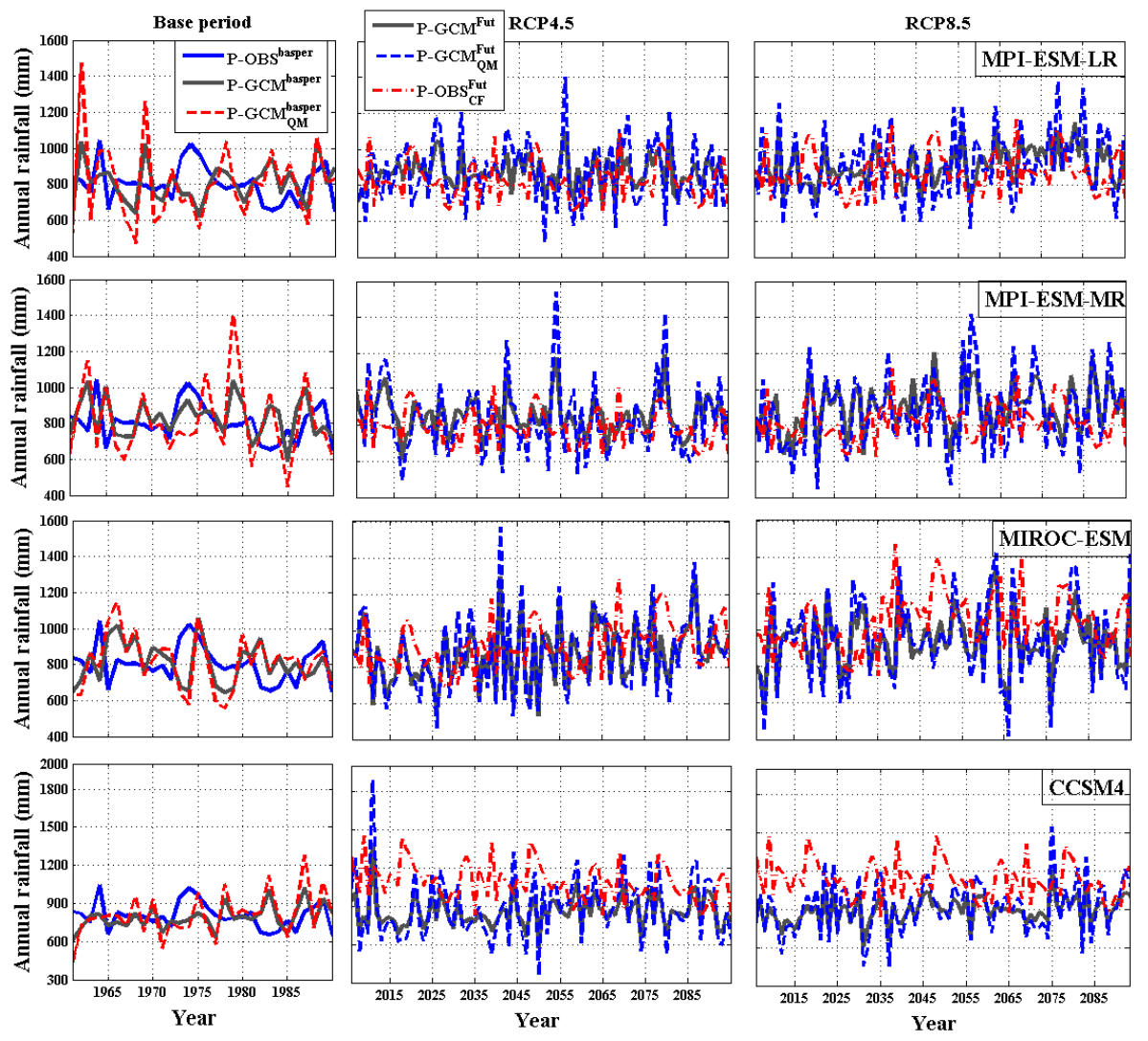

Figure 10. As in Fig. 7 but for the rainfall.

the main factor in the wetland ecosystem alteration, and accordingly influence all the ecosystem components. This is consistent with Woo et al. (1993), who pointed out that the fate of the wetlands under climate change mainly depends on changes in external recharge that are related to alterations in precipitation and evaporation over the wetland itself. Moreover, comparatively tiny increments in precipitation change can significantly influence wetland flora and fauna at various phases of their life cycles (Keddy, 2000). As a result, the entire wetland's ecosystem was affected by alterations in precipitation and streamflow (Bauder, 2005). Therefore, according to the seasonality of the DR, a small decrease or increase in the annual rainfall leads to a decline or increment in the water level, and the impact will extend to the next seasons, as happened during the drought periods.

The rainfall over the DRB during the first drought period (1964 to 1972) declined by about 23 and $11 \%$, respectively, which led to a decline in the runoff of about $9.8 \%$ during 1972 to 1977 . The second wave of drought lasted from 1976 to 1987 and decreased the rainfall by about $14.8 \%$, leading to a decrease in the runoff of about $42.25 \%$ compared to the baseline period (1961 to 1971). These alterations caused a sharp decline in the DR runoff and seriously affected the water availability in many mayas. Moreover, the waves of drought followed by a flood season led to the remarkable damage in the river stream by closing the channels' feeder from the main stream to the mayas and increasing the erosion and sedimentation. Consequently, it decreased the water amounts, and many of the mayas dried. There are about 40 mayas distributed in the DNP, such as Ras Amir, Gadahat, and Godah, influenced by alterations in the rainfall trend during drought periods. Ras Amir, considered to be the largest maya $\left(4.5 \mathrm{~km}^{2}\right)$, dried up during the drought periods (1970s) and since that time has become haphazardly less enduring every few years and full of water in other years. Farash el Naam is the second biggest maya $\left(1.6 \mathrm{~km}^{2}\right)$; after drought periods (1980s) it became more inconstant and less permanent. The last one is Godaha, which consists of a series of eleven small mayas; Godahat is the major one $\left(0.2 \mathrm{~km}^{2}\right)$, and was affected by the drought period as well (Hakim et al., 1978; Abdel Hameed, 1983; Abdel Hameed et al., 1997; Abdel Hameed and Eljack, 2003). Thus, changes in temperature, precipitation, and streamflow magnitude affected the sustainability of the ecosystem in terms of the habitats' components in the DNP. Consequently, the damage in habitats impacted most of the flora and fauna in the DNP.

In this century, the DNP habitats will virtually certainly be exposed to the climate change impact, such as temperature increment or rainfall increase and/or decline, which will very 


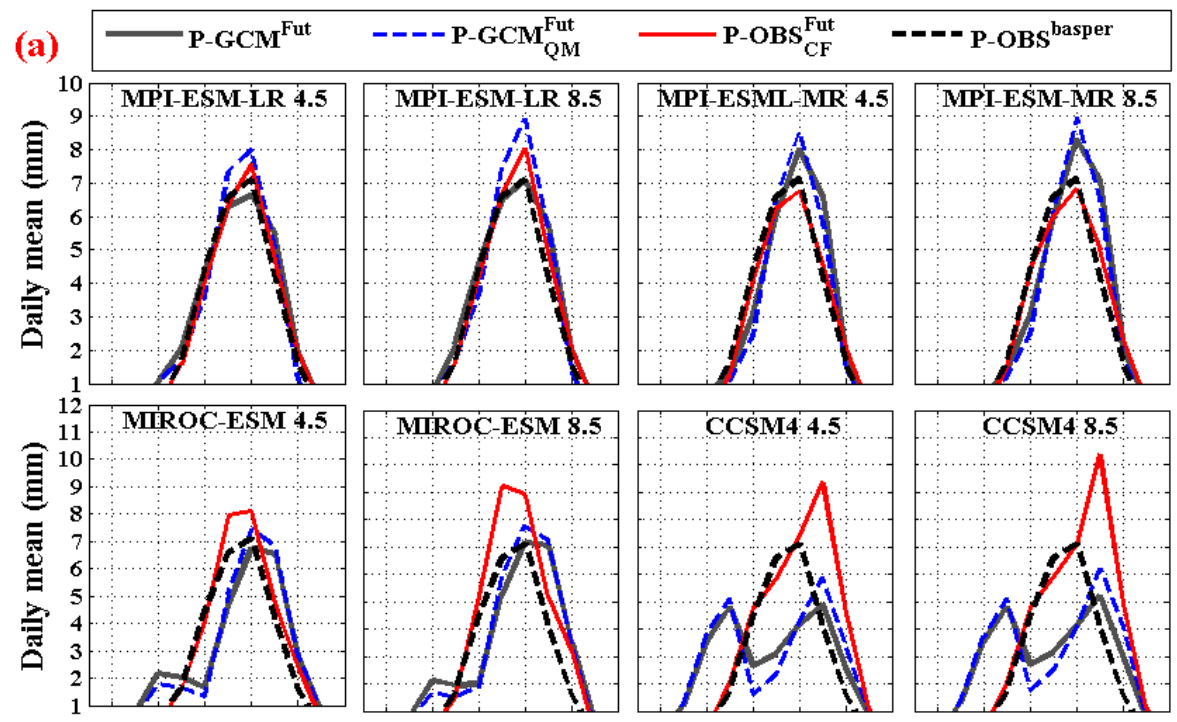

(b)
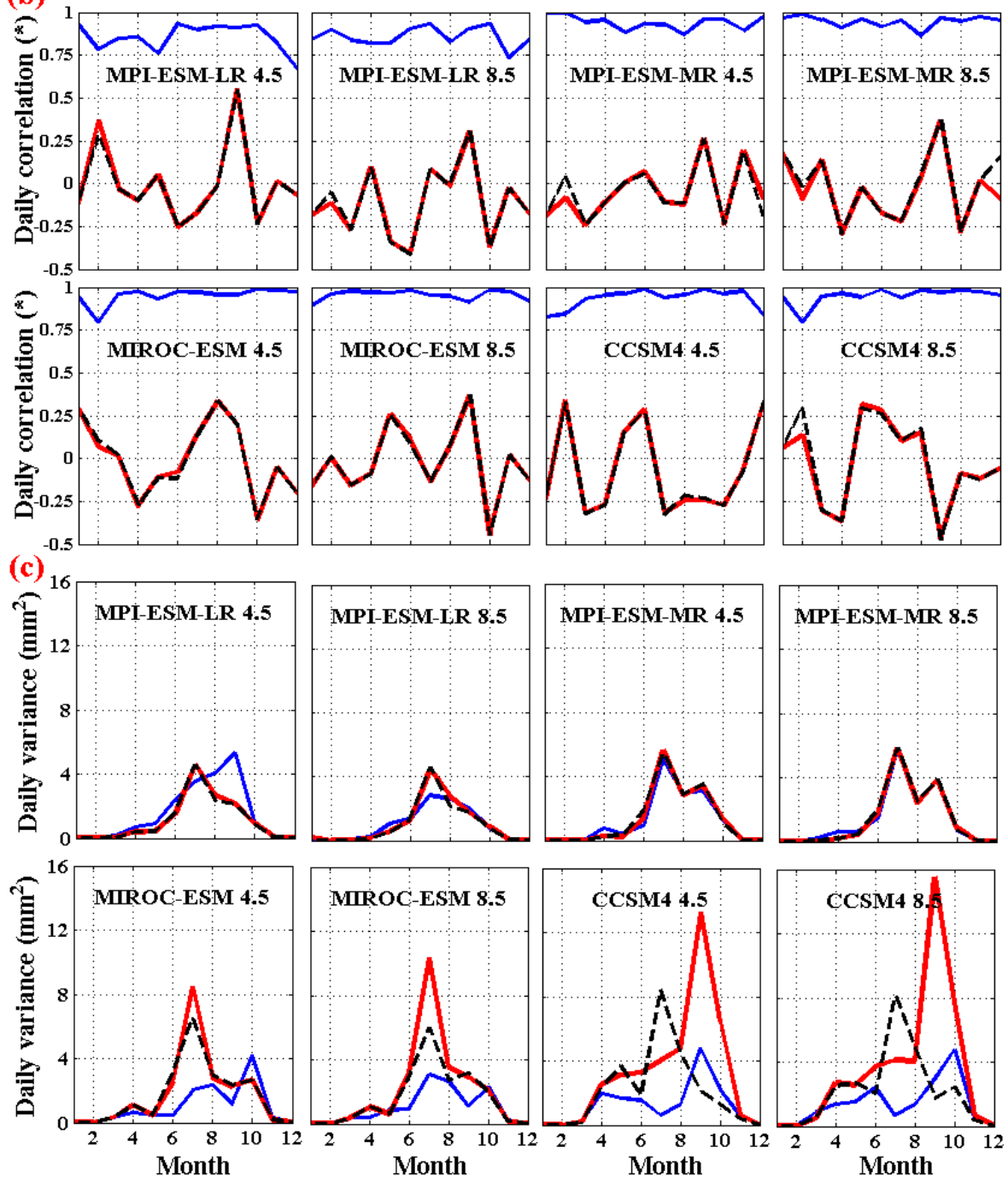

Figure 11. As in Fig. 9 but for the rainfall. 


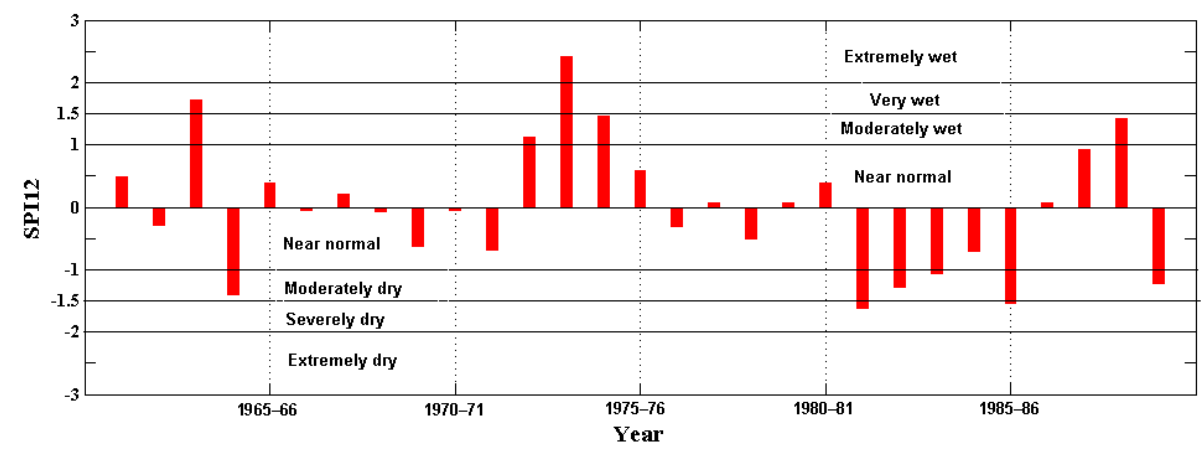

Figure 12. Historical time series of the SPI for a long-term scale.

Table 5. Annual changes in $T_{\max }$ in the future under the four GCMs and two scenarios (RCP4.5 and RCP8.5).

\begin{tabular}{|c|c|c|c|c|c|c|c|c|}
\hline \multirow{3}{*}{$\begin{array}{l}\text { Periods } \\
\text { RCP } 4.5\end{array}$} & \multicolumn{8}{|c|}{ Annual change in $T_{\max }\left({ }^{\circ} \mathrm{C}\right)$} \\
\hline & \multicolumn{4}{|c|}{ CF method } & \multicolumn{4}{|c|}{ QM method } \\
\hline & MPI-ESM -LR & MPI-ESM-MR & MIROC-ESM & CCSM4 & MPI-ESM-LR & MPI-ESM-MR & MIROC-ESM & CCSM4 \\
\hline 2020 s & 1.4 & 1.2 & 0.9 & 0.9 & 1.7 & 1.2 & 0.7 & 0.8 \\
\hline $2050 \mathrm{~s}$ & 2.4 & 2.4 & 1.5 & 1.5 & 2.7 & 2.4 & 1.3 & 1.5 \\
\hline $2080 \mathrm{~s}$ & 3.0 & 2.9 & 1.9 & 1.7 & 3.2 & 2.9 & 1.6 & 1.7 \\
\hline \multicolumn{9}{|l|}{ RCP 8.5} \\
\hline $2020 \mathrm{~s}$ & 1.6 & 1.4 & 0.6 & 1.0 & 1.8 & 1.5 & 0.6 & 1.2 \\
\hline $2050 \mathrm{~s}$ & 2.9 & 2.9 & 1.4 & 1.9 & 3.2 & 3.0 & 1.3 & 2.1 \\
\hline $2080 \mathrm{~s}$ & 4.9 & 4.8 & 3.3 & 3.5 & 5.2 & 4.7 & 3.3 & 3.7 \\
\hline
\end{tabular}

likely affect the flora and fauna and their migration, blooming, and mating timing.

\subsection{Future climate change}

The CF and QM methods were employed to downscale the climate variables (temperature and precipitation) for the selected GCMs.

\subsubsection{Mean of $T_{\max }$ and $T_{\min }$}

The future climate conditions were determined using the combination of climate change scenarios (RCP 4.5 and RCP 8.5 ) and four GCM models. Tables 5 and 6 represent the difference between projected $T_{\max }$ and $T_{\min }$ and the baseline period (1961-1990) when the CF and QM methods were applied. $T_{\max }$ and $T_{\min }$ project a more consistent change trend than precipitation. Stability increases were projected for each variable ( $T_{\max }$ and $T_{\min }$ ) by all the models and two emissions scenarios in the future. The $T_{\max }$ trend analysis shows an obvious increment under the two downscaling approaches in the future. For annual mean $T_{\max }$ and $T_{\min }$, the MPI-ESM-LR gave the largest increases and MIROC-ESM gave the lowest increases in the future under the two downscaling approaches and scenarios. By using the QM and CF methods, the projected $T_{\max }$ increase ranges are between 0.9 and 1.8, 1.3 and
3.2 , and 1.6 and $5.2^{\circ} \mathrm{C}$ in the $2020 \mathrm{~s}, 2050 \mathrm{~s}$, and $2080 \mathrm{~s}$, respectively. For the annual $T_{\min }$ the four models' projected increase ranged from 0.9 to $1.8^{\circ} \mathrm{C}$, from 1.6 to $3.3^{\circ} \mathrm{C}$, and from 1.7 to $5.3^{\circ} \mathrm{C}$ in the $2020 \mathrm{~s}, 2050 \mathrm{~s}$, and $2080 \mathrm{~s}$, respectively. The RCP8.5 scenario under the QM and CF projected higher temperature increases than the RCP4.5 scenario in the whole periods, whereas the 2080s period showed the highest increase change in temperature based on the four models. Broadly, the expected temperature under different climate change scenarios and conditions indicate that the overall climate will become much warmer as time passes. This result was consistent with the conclusions of Elshamy et al. (2009), Taye and Willems (2013), and Enyew et al. (2014), which indicated that the temperature projected by multi-GCMs will increase over the Upper Blue Nile.

\subsubsection{Mean precipitation}

Table 7 illustrates the projected change in the annual precipitation under the four GCMs and the two scenarios (RCP4.5 and RCP8.5) using the CF and QM downscaling approaches. For annual precipitation, all GCMs projected an increase under the two downscaling methods, RCPs, and three periods corresponding to the drought period (1977-1988). Mean annual precipitation projected by the CCSM4 and MIROCESM models generated a dramatic increase when the $\mathrm{CF}$ 
Table 6. Annual changes in $T_{\min }$ in the future under the four GCMs and two scenarios (RCP4.5 and RCP8.5).

\begin{tabular}{|c|c|c|c|c|c|c|c|c|}
\hline \multirow{3}{*}{$\begin{array}{l}\text { Periods } \\
\text { RCP } 4.5\end{array}$} & \multicolumn{8}{|c|}{ Annual change in $T_{\min }\left({ }^{\circ} \mathrm{C}\right)$} \\
\hline & \multicolumn{4}{|c|}{ CF method } & \multicolumn{4}{|c|}{ QM method } \\
\hline & MPI-ESM-LR & MPI-ESM-MR & MIROC-ESM & CCSM4 & MPI-ESM-LR & MPI-ESM-MR & MIROC-ESM & CCSM4 \\
\hline $2020 \mathrm{~s}$ & 1.4 & 1.4 & 1.2 & 0.9 & 1.6 & 1.3 & 1.2 & 1.0 \\
\hline $2050 \mathrm{~s}$ & 2.4 & 2.6 & 2.0 & 1.6 & 2.6 & 2.4 & 1.9 & 1.9 \\
\hline $2080 \mathrm{~s}$ & 2.9 & 3.1 & 2.5 & 1.7 & 3.1 & 2.9 & 2.5 & 2.1 \\
\hline \multicolumn{9}{|l|}{ RCP 8.5} \\
\hline $2020 \mathrm{~s}$ & 1.6 & 1.7 & 1.0 & 1.0 & 1.8 & 1.5 & 1.0 & 1.5 \\
\hline $2050 \mathrm{~s}$ & 3.0 & 3.3 & 2.1 & 1.9 & 3.2 & 2.9 & 2.2 & 2.7 \\
\hline $2080 \mathrm{~s}$ & 5.1 & 5.3 & 4.3 & 3.4 & 5.3 & 4.9 & 4.3 & 4.4 \\
\hline
\end{tabular}

Table 7. Annual changes in precipitation in the future under the RCP4.5 and RCP8.5 scenarios for the GCMs.

\begin{tabular}{|c|c|c|c|c|c|c|c|c|}
\hline \multirow{3}{*}{$\begin{array}{l}\text { Periods } \\
\text { RCP } 4.5\end{array}$} & \multicolumn{8}{|c|}{ Annual change in precipitation (\%) } \\
\hline & \multicolumn{4}{|c|}{ CF method } & \multicolumn{4}{|c|}{ QM method } \\
\hline & MPI-ESM-LR & MPI-ESM-MR & MIROC-ESM & CCSM4 & MPI-ESM-LR & MPI-ESM-MR & MIROC-ESM & CCSM4 \\
\hline $2020 \mathrm{~s}$ & 8.1 & 5 & 11 & 48.4 & 13.1 & 10.3 & 7.8 & 12 \\
\hline $2050 \mathrm{~s}$ & 7.2 & 3.2 & 18.4 & 43 & 13.6 & 7.1 & 12.9 & 14.7 \\
\hline $2080 \mathrm{~s}$ & 8.9 & 2.6 & 29.9 & 35.4 & 14.8 & 7.4 & 19.1 & 17 \\
\hline \multicolumn{9}{|l|}{ RCP 8.5} \\
\hline $2020 \mathrm{~s}$ & 10.8 & 9 & 24.2 & 50.6 & 14 & 7.5 & 11.1 & 14.3 \\
\hline 2050 s & 15.4 & 12.3 & 48.1 & 47.7 & 17.2 & 15.7 & 26 & 20.7 \\
\hline 2080 s & 16.7 & 9.5 & 38.2 & 44 & 25.3 & 16.8 & 22 & 21.7 \\
\hline
\end{tabular}

method is applied, while the MPI-ESM-LR and MPI-ESMMR models showed a significant upward trend. The four models with the QM method and the two RCPs showed a significant and convergent increase during the three periods. The mean annual precipitation changes using the $\mathrm{CF}$ method for the four GCMs ranged from 5 to $48.4 \%$, from 3.2 to $43 \%$, and from 2.6 to $35.4 \%$ under RCP4.5 for the three periods, respectively, whereas under RCP8.5 changes ranged from 9 to $50.9 \%$, from 12.3 to $48.1 \%$, and from 9.5 to $44 \%$ in the 2020s, 2050s, and 2080s, respectively. Conversely, mean annual precipitation projected by using the QM method showed a convergent significant upward trend with the four models. The four models generated increments ranging from 7.8 to $13.1 \%$, from 7.1 to $14.7 \%$, and from 7.4 to $19.1 \%$ under RCP4.5 for the three periods, respectively, whereas under RCP8.5 changes ranged from 7.5 to $14.3 \%$, from 15.7 to $26 \%$, and from 16.8 to $25.3 \%$ in the 2020 s, 2050s, and 2080s, respectively. Scenario RCP8.5 always suggests a greater increase in precipitation than in RCP4.5, especially in the 2080s. In general, results showed that the alterations in precipitation amount increase for some months of the year, while they decrease for the other months. Among the future years, the MIROC-ESM, CCSM4, and MPI-ESMLR with the two downscaling methods and RCPs showed the largest values in the 2080s. The predicted change magnitudes of the annual precipitation for the four GCMs and the two RCPs using QM methods were consistent during the three periods. Broadly, the four GCMs projected upward trends in the annual precipitation in this century. The CCSM4 and MIROC-ESM showed a dramatic increase when the CF method is applied, which may be attributed to the difference between the rainfall pattern in the historical period for the GCM model and the study area in some months. In general, studies by Elshamy et al. (2009), Beyene et al. (2010), Taye et al. (2011), and Enyew et al. (2014) indicated that the directions of projected precipitation changes are mixed and highly variable both from sub-basin to sub-basin and from season to season over the Upper Blue Nile basin.

\subsubsection{Response of streamflow to climate change}

The highest flow decline that was observed to be more influential on the DNP ecosystem habitats was during two drought periods. Accordingly, comparing streamflow in the future periods with the average simulated for the drought periods could produce more reliable results rather than comparing it with periods including extreme flood years. Therefore, the drought period from 1977 to 1988 that has a low average flow rate (except for 1988) was set as the baseline period 
Table 8. Possible annual streamflow changes in the future years (2020s, 2050s and 2080s) of the DRB.

\begin{tabular}{|c|c|c|c|c|c|c|c|c|}
\hline \multirow{3}{*}{$\begin{array}{l}\text { Periods } \\
\text { RCP } 4.5\end{array}$} & \multicolumn{8}{|c|}{ Annual change in streamflow (\%) } \\
\hline & \multicolumn{4}{|c|}{ CF method } & \multicolumn{4}{|c|}{ QM method } \\
\hline & MPI-ESM-LR & MPI-ESM-MR & MIROC-ESM & CCSM4 & MPI-ESM-LR & MPI-ESM-MR & MIROC-ESM & CCSM4 \\
\hline $2020 \mathrm{~s}$ & 23.5 & 15.3 & 29.5 & 87.9 & 9.2 & -2.1 & -9.4 & -8.5 \\
\hline $2050 \mathrm{~s}$ & 19.9 & 4.7 & 55.0 & 78.1 & 5.1 & -3.45 & -2.1 & -0.41 \\
\hline $2080 \mathrm{~s}$ & 26.5 & 2.5 & 66.4 & 82.8 & 11.4 & 4.2 & 12.3 & -5.7 \\
\hline \multicolumn{9}{|l|}{ RCP 8.5} \\
\hline $2020 \mathrm{~s}$ & 27.3 & 0.3 & 61.3 & 86.7 & 3.1 & -7.1 & 13.4 & -11.9 \\
\hline $2050 \mathrm{~s}$ & 37.1 & 23.2 & 78.2 & 71.0 & 5.9 & 10.8 & 38.9 & 3.1 \\
\hline $2080 \mathrm{~s}$ & 44.3 & 17.0 & 81.3 & 87.6 & 22.4 & 6.9 & 15.7 & 9.0 \\
\hline
\end{tabular}
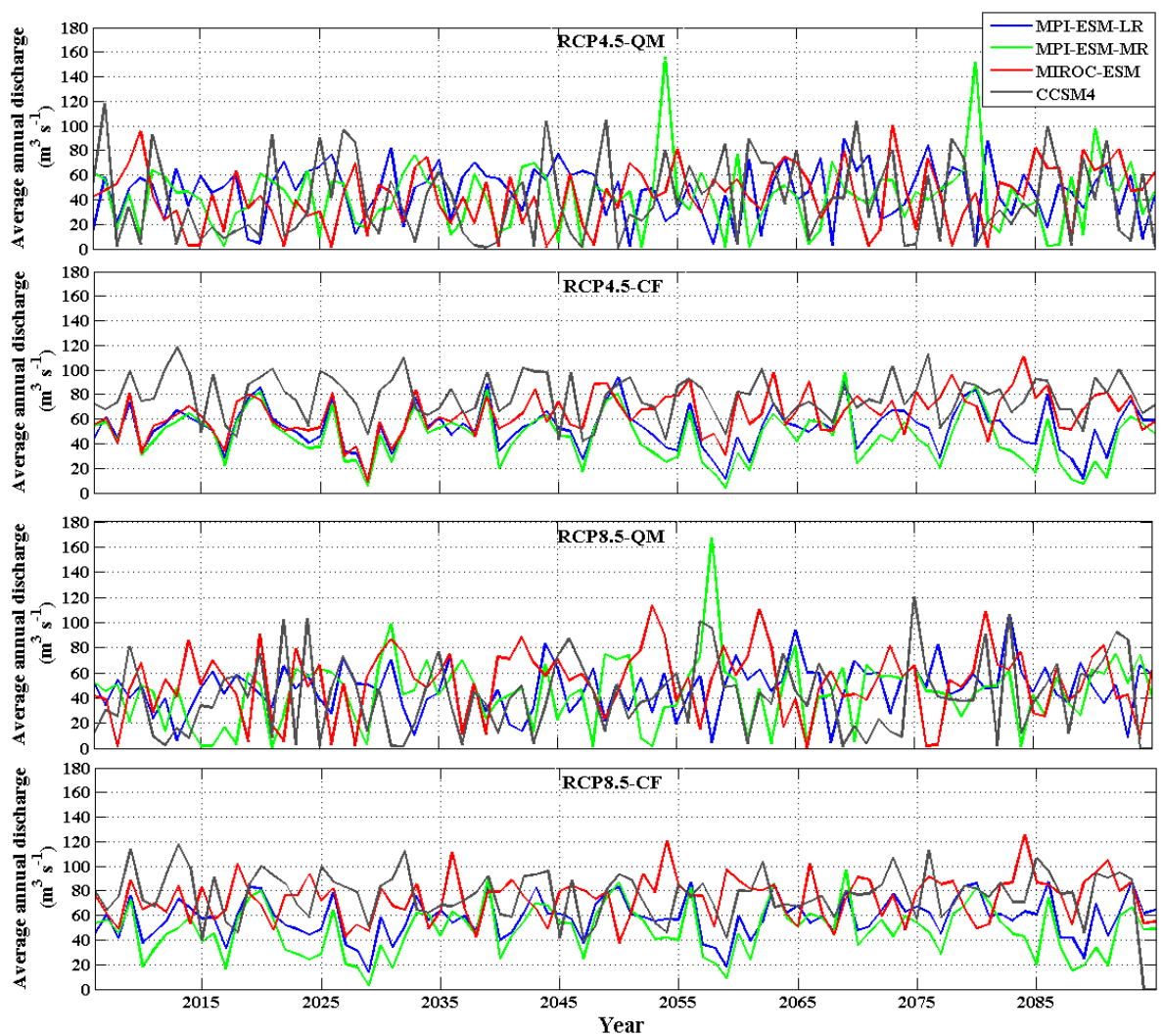

Figure 13. Possible changes in the average annual discharge cycle (on a monthly basis) at the upstream portion of the DRB for the four models when the two downscaling (QM and CF) methods were applied.

in this study. The potential effect of future climate change on annual streamflow generated by the outputs of the four models and two downscaling approaches is shown in Table 8 and Fig. 13. It can be seen that the expected change rates in the 2020s, 2050s, and 2080s range from 0.3 to $87.9 \%$, from 4.7 to $78.1 \%$, and from 2.5 to $87.6 \%$, respectively, for the four models when the CF approach is applied, while the possible annual streamflow changes in the same period, when the QM method is applied, are predicted to fluctuate from -11.9 to $9.2 \%$, from -3.45 to $38.9 \%$, and from -5.7 to $22.4 \%$. With the two downscaling methods, the RCP8.5 scenario indicated a greater increase in runoff than RCP4.5, particularly in the 2080s. The streamflow projected by the MPI-ESM-LR and MPI-ESM-MR under the two downscaling methods showed a consistent changing trend with precipitation, particularly when the QM was applied. However, the CCSM4 and MIROC-ESM models with the CF method predicted a significant increasing trend in the annual streamflow, in contrast to the QM method. The CCSM4 and MIROC-ESM models under the QM and the RCP4.5 
scenario showed decreases in the future periods, except for the 2080s for the MIROC-ESM, which gave a significant increase. Meanwhile, under RCP8.5 the streamflow suggested remarkable increments, except for the 2020s period for the CCSM4 model, which showed a significant decline. The increment that is predicted by the CF approach is seemingly due to its high rainfall projection. For the monthly scale, streamflow projected by MPI-ESM-LR and the CF method showed reasonable variability in June and October, from 4.8 to $2.73 \mathrm{~m}^{3} \mathrm{~s}^{-1}$ and from 47.64 to $111 \mathrm{~m}^{3} \mathrm{~s}^{-1}$, respectively, and the change range is $\pm 46 \%$ in all other months. However, by applying the QM method, streamflow increased significantly in October, from 47.64 to $107 \mathrm{~m}^{3} \mathrm{~s}^{-1}$, while other months fluctuated within $\pm 39 \%$. The MPI-ESM-MR model through the CF method suggested reasonable variability in streamflow in June and October, from 4.8 to $5.1 \mathrm{~m}^{3} \mathrm{~s}^{-1}$ and from 47.64 to $77.1 \mathrm{~m}^{3} \mathrm{~s}^{-1}$, respectively, and alterations range within $\pm 84 \%$ in all other months, while by applying the QM method, streamflow increased significantly in October from 47.64 to $140 \mathrm{~m}^{3} \mathrm{~s}^{-1}$, while other months fluctuated within $\pm 95 \%$. The mean monthly streamflow projected by the CF method in the 2020s under the CCSM4 and MIROC-ESM models showed remarkable increases in June and October from 4.8 to $7.9 \mathrm{~m}^{3} \mathrm{~s}^{-1}$ and from 47.64 to $165.1 \mathrm{~m}^{3} \mathrm{~s}^{-1}$, respectively, and varied with a percentage rate of $87 \%$ in the other months, while by applying the QM method to the same models, monthly streamflow in June and October was observed to increase from 4.8 to 5.4 and from 47.64 to $160 \mathrm{~m}^{3} \mathrm{~s}^{-1}$, respectively, and fluctuated within $\pm 93 \%$ in the other months. Although the percentage of streamflow increment in 2050s was somewhat less than that of the 2020s, the prediction of the four GCMs and the two approaches generally showed a similar upward trend in the two periods. Similarly to the 2020s and 2050s, the monthly streamflow predictions for the future period of the 2080s showed an upward trend with a slight difference in the magnitude in some months compared to the baseline period. The high percentage of change in monthly streamflow displayed by the CCSM4 and MIROC-ESM models under the CF and QM approaches could be attributed to the uncertainty of the models and the difference in the pattern of some monthly rainfall between the model and the study area. Furthermore, the DR is a seasonal river (June-October) flowing from elevation 2646 to $400 \mathrm{~m}$; thus, runoff is rapid and a small amount of precipitation is retained by deep percolation (UNESCO, 2004). Moreover, as a mountainous region, the streamflow in the DR showed high sensitivity to precipitation changes, particularly in the last 5 decades. Although the CCSM4 and MIROC-ESM models under the QM method and RCP4.5 showed an increment in rainfall projection in the three periods, the streamflow projected decrease. This could be due to the uncertainty in hydrological model parameters. Among the four models, MPI-EMI-LR and MPI-ESM-MR projected a reasonable increment in streamflow over the study area.
Despite the projected streamflow varying between increase and decline, the increase trend was the dominant characteristic in streamflow prediction. Based on the results obtained in this study, there is uncertainty in the simulated streamflow under given climate change conditions; this uncertainty can be attributed to different sources of variability represented in future emissions scenarios, GCM projections, downscaling approaches, and hydrological model parameterization.

\subsubsection{Future dryness and wetness patterns over the DRB}

The future rainfall time series projected by the four GCMs and the two downscaling approaches were analyzed by applying the SPI-12 to investigate the hydrological wetness/dryness events (Figs. 14 and 15). In general, the future dryness/wetness of the DRB showed a different trend than the past. Results showed that, compared to the baseline period, severely dry and very wet conditions are expected to increase, but the duration is expected to decrease. In the other words, dry/wet conditions will likely become more frequent during the next 10 decades; i.e., it recurs at shorter time intervals, in particular when the QM approach is applied. However, for the future projected using the CF methods, the dryness/wetness suggested a symmetric pattern to the baseline period (Fig. 15). For the MPI-ESM-LR model under the QM method and the two RCP scenarios, the annual dryness/wetness events during three periods are projected to range from 10 to $23 \%$ (moderately, severely, and extremely) dry and from 10 to $24 \%$ (moderately, very, and extremely) wet, while the remaining ones are near moderate. Moreover, dry/wet conditions are likely to become less frequent, but it presumably will increase in terms of severity, particularly in the 2050s. For the MPI-ESM-MR model under the QM method, the percentage of dry years is suggested to range between 7 and $23 \%$, while the wet ones (moderately, very and extremely) ranged between 13 and $23 \%$. The RCP4.5 scenario in the 2050s and 2080s gave extreme dry and wet events, while the RCP8.5 scenario predicted the same events in the 2050s. The dry conditions that were projected by the MIROC-ESM model using the QM method were found to range from 6 to $20 \%$ (moderately, severely, and extremely), whilst wet conditions ranged from 10 to $23 \%$ (moderately, very, and extremely) during the three periods. Under RCP8.5 and the QM method, the 2050s and 2080s suggested a long duration of severe and moderate droughts. Regarding the CCSM4 model under the RCP8.5 scenario and the QM method, the 2020s are projected to have moderately and severely dry conditions ( $27 \%$ ), whereas the wetness condition was found to be $7 \%$. Conversely, the 2080s showed the highest percentage of wetness events $(30 \%)$, while the dryness events were $16 \%$. 


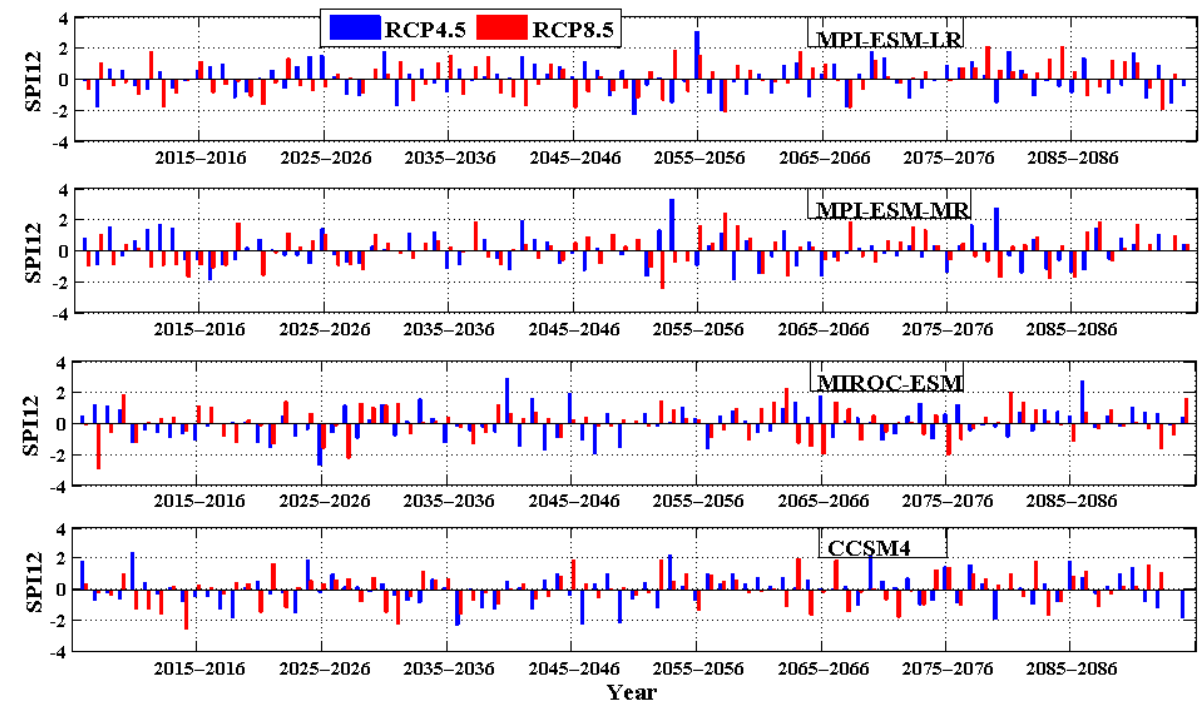

Figure 14. Future time series of SPI-12 (long-term scale) for rainfall projected by the four models and two scenarios (RCP4.5 and RCP8.5) when the QM approach is applied.
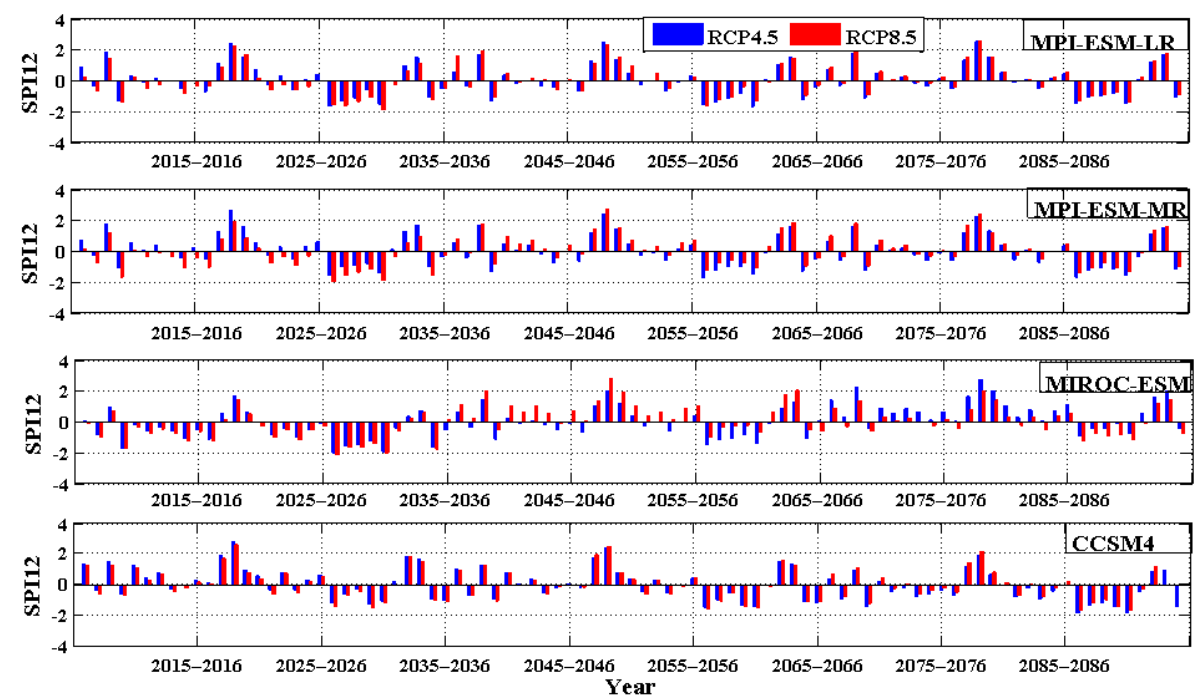

Figure 15. As in Fig. 14 but when the CF approach is applied.

\subsubsection{Impact of projected climate change on DNP ecosystem habitats}

Based on the climate change projection scenarios, the changes in temperature and precipitation will impact either directly or indirectly the streamflow magnitude. Consequently, the DNP ecosystem will very likely be exposed to a variety of negative and positive effects, based on these projections. Although climatic warming in this century is expected to start a drying trend in wetland ecosystems in most parts of the world (Gorham, 1991), the results obtained by this work showed that the DRB wetlands will experience an increment in water magnitude according to the projected increment in the annual rainfall and streamflow. Generally, the temperature increase and greater changes in precipitation will occur in the DNP over this century. The four GCMs projected annual increases in $T_{\max }$ ranging from 0.9 to $4.9^{\circ} \mathrm{C}$ and in $T_{\text {min }}$ ranging from 0.9 to $5.3^{\circ} \mathrm{C}$, whilst the RCP8.5 scenario projected the greatest increase. Alterations in precipitation are projected to temporally vary when the CF and QM approaches are applied between 2.6 and $50.6 \%$ and between 7.1 and $26 \%$, respectively. The DNP is expected to get drier in the summer, whereas it is more likely to be wetter in fall. The rainfall increment will be greater in the southeastern part of the DNP than in the northwest. Moreover, the maximum magnitude of precipitation will likely increase as well. 
The upward trend in the rainfall amount predicted by the four models will have distinctly positive impacts on the DNP ecosystems in terms of habitat sustainability of many living organisms. The four GCM models, when the CF and QM approaches are applied, projected an increase in rainfall over the DRB ranging between 2.6 and $50.6 \%$ and between 7.1 and $26 \%$, respectively, which will likely lead to an increment in streamflow. Furthermore, the long duration of hydrological dryness that happened in the past that led to the huge impact in the DNP ecosystem was projected to decrease. These increases in the streamflow likely will be suitable amounts for restoration of the DNP ecosystem components. The DNP lies on the road of winter migration for many African birds during their passage to eastern Africa Rift Valley lakes or southward. Accordingly, the increase in water during the flood season in this century will lead to an increase in the capacity of the mayas and pools to receive greater numbers of these migrant birds. Furthermore, these habitats will not be a breedeffective threat to the life cycle for that birds or a defect in the ecosystem balance of the DNP and the regional scale. Apart from this, the four GCM predictions indicated that precipitation most probably will tend to increase in the future over the DNP. Consequently, this positive variation will likely greatly influence the water level in the mayas and pools and promote the intensity of vegetation cover and growth of the grasses that are considered to be a major food source for most the DNP fauna.

The analysis presented here indicates that the four GCMs and the two scenarios projected significant annual and monthly increments in temperature. This increment will likely affect the habitats' component in the DNP, as the water level will be affected by the evapotranspiration over the DRB, particularly under the MPI-ESM-LR and MPI-ESMMR models and the RCP8.5 scenario at the end of this century.

According to the projected alterations in the temperature, precipitation, and streamflow, we expected that the DNP ecosystem events and habitats will very likely be shifted. In fact, the spatial and temporal variations of the temperature and precipitation over the DNP offer the DNP ecosystem the same habitat with different climatic conditions. Consequently, most of the fauna and flora have a high resilience to adapt to the impact of the climate change and habitat loss as happened during drought periods. This implies that during drought periods some of the fauna and flora have changed their habitats to the areas that have the same climate conditions as their previous habitats as a form of adaptation. Furthermore, over the last 100 years, maximum temperature with mean rainfall as a secondary driver was the determining factor in habitat loss and fragmentation, averaged across species and geographic regions. Habitat loss and fragmentation effects were greatest in areas with high maximum temperatures. Conversely, they were lowest in areas where average rainfall has increased over time (Mantyka-pringle et al., 2012). Based on the projected climate determinants and the DNP ecosystem characteristics, it can be concluded that ecosystem components will likely be expected to start restoration of ecosystem habitats.

\section{Conclusions}

This paper analyzed the response of streamflow and ecosystem habitats in the DRB to possible future climate condition change that was predicted by using four GCMs coupled with two downscaling approaches and a physically based distributed hydrologic model (SWAT). Moreover, the future rainfall time series projected by the four GCMs were analyzed by applying the SPI-12 to estimate the hydrological dryness/wetness events over the DRB during three periods. Predictions of the four GCMs pointed out that the temperature and precipitation will increase in the next century, while the severe dry and very wet events of short durations are predicted to be more frequent in the future. Consequently, the streamflow is likely to increase according to the rainfall increase. The type of the used downscaling approach was the key factor in climatic variable projection. The annual rainfall predicted by using the QM approach based on the four GCM models tends to have the same increasing trend, particularly under the RCP8.5 scenario. The CF approach showed a huge increment, with the CCSM4 and MIROC-ESM models corresponding to the other models. In contrast, the MPIESM-LR and MPI-ESM-MR models under the CF and QM approaches predicted a convergent annual rainfall upward trend. The similarity of the result obtained by applying the QM method for the four GCM models was attributed to the fact that the QM approach takes into account daily rainfall time series generated by the GCM. There is uncertainty in the streamflow projection basically depending on the GCMs, scenarios, downscaling approach, and model parameterization. Relying on prediction of potential possible changes in climate condition, ecosystem components in the DNP substantially will likely be affected in a way that cause living organism habitats and life cycle to have recovery conditions rather than extinction and destruction circumstances, as was happening during the drought periods (1960s, 1970s, and 1980s). On the other hand, the projected rainfall and the seasonality of the river will cause a more uneven distribution of annual flow from year to another. Thus, a strong focus on extreme events (floods and drought) to avoid the negative hydrological effect on the DNP ecosystem habitats should be considered. This study projected the hydroclimatic condition over the DNP and assessed how ecosystem habitats respond to the changes in these variables. Despite the presence of the uncertainties, the results provide benchmark information that can be used to increase the capacity of the water resource management and ecosystem conservation strategies by identifying suitable actions for the future, that is, to create more resilience to climate changes related to habitat restoration and continued management of other stressors in the DNP 
ecosystem. Furthermore, the integrity of hydrological conditions in the DR stream and mayas should be considered, to reduce the negative impact of climate change on fragmented wetlands' ecosystems, particularly in terms of dryness and wetness events. Finally, this work would offer quite useful information required by rain-fed agriculture, hydrologists, ecologists, and zoologists for further studies.

Acknowledgements. The authors would like to thank the Sudan Ministry of Water Resources \& Electricity, the Wildlife Research Centre, Meteorological Authority and Nile basin initiative for providing us with the data. Thanks to Fen Ouyang, PhD student at the College of Hydrology and Water Resources, Hohai University, China, and Elhassan Zakieldeen, Karary University, Engineering College, Sudan, for their technical assistance. This study is supported by the National Natural Science Foundation (41371049; 41571015; 41323001; 51190091) and the National Basic Research Program of China (2013CBA01806).

The authors appreciate the great effort of K. Hassaballah and the second anonymous referee for their valuable comments and suggestions.

Edited by: S. Uhlenbrook

\section{References}

Abbaspour, K. C., Yang, J., Maximov, I., Siber, R., Bogner, K., Mieleitner, J., Zobrist, J., and Srinivasan, R.: Modelling hydrology and water quality in the pre-alpine/alpine Thur watershed using SWAT, J. Hydrol., 333, 413-430, 2007.

Abdel Hameed, S. M.: Vegetation of the mayas of Dinder National Park, Sudan, Colorado State University, 1983.

Abdel Hameed, S. M. and Eljack, A. O.: Ramsar Information Sheet (RIS) for Dinder national park, Sudan, Wetlands International Global, available at: https://rsis.ramsar.org/RISapp/files/RISrep/ SD1461RIS.pdf (last access: April 2015), 2003.

Abdel Hameed, S. M., Awad, N. M., ElMoghraby, A. I., Hamid, A. A., Hamid, S. H., and Osman, O. A.: Watershed management in the Dinder National Park, Sudan, Agr. Forest Meteorol., 84, 89-96, 1997.

Arnold, J. G., Srinivasan, R., Muttiah, R. S., and Williams, J. R.: Large area hydrologic modeling and assessment part I: Model development ${ }^{1}$, Wiley Online Library, 1998.

Bauder, E.: The effects of an unpredictable precipitation regime on vernal pool hydrology, Freshwater Biol., 50, 2129-2135, 2005.

Beyene, T., Lettenmaier, D. P., and Kabat, P.: Hydrologic impacts of climate change on the Nile River Basin: implications of the 2007 IPCC scenarios, Climatic change, 100, 433-461, 2010.

Burkett, V. R., Wilcox, D. A., Stottlemyer, R., Barrow, W., Fagre, D., Baron, J., Price, J., Nielsen, J. L., Allen, C. D., and Peterson, D. L.: Nonlinear dynamics in ecosystem response to climatic change: case studies and policy implications, Ecol. Complex., 2, 357-394, 2005.

Camici, S., Brocca, L., Melone, F., and Moramarco, T.: Impact of climate change on flood frequency using different climate models and downscaling approaches, J. Hydrol. Eng., 19, 04014002, doi:10.1061/(ASCE)HE.1943-5584.0000959, 2013.
Charlton, R., Fealy, R., Moore, S., Sweeney, J., and Murphy, C.: Assessing the impact of climate change on water supply and flood hazard in Ireland using statistical downscaling and hydrological modelling techniques, Climatic Change, 74, 475-491, 2006.

Chow, V. T., Maidment, D. R., and Mays, L. W.: Applied hydrology, McGraw-Hill Series in Water Resources and Environmental Engineering, McGraw-Hill, New York, 572 pp., 1988.

Cramér, H.: Mathematical methods of statistics, Princeton university press, 1999

Dasmann, W.: Development and management of Dinder National Park and its Wildlife, Food and Agriculture Organisation, Rep, 3113, 2-62, 1972.

Dessu, S. B. and Melesse, A. M.: Impact and uncertainties of climate change on the hydrology of the Mara River basin, Kenya/Tanzania, Hydrol. Process., 27, 2973-2986, 2013.

Diaz-Nieto, J. and Wilby, R. L.: A comparison of statistical downscaling and climate change factor methods: impacts on low flows in the River Thames, United Kingdom, Climatic Change, 69, 245-268, 2005.

Döll, P. and Zhang, J.: Impact of climate change on freshwater ecosystems: a global-scale analysis of ecologically relevant river flow alterations, Hydrol. Earth Syst. Sci., 14, 783-799, doi:10.5194/hess-14-783-2010, 2010.

El Moghraby, A. and Abdu, A.: The Dinder National Park, study area. Final report, Environmental management in the Sudan. Institute of Environmental Studies, University of Khartoum Reports, 45, 1985.

Elagib, N. A.: Meteorological drought and crop yield in subSaharan Sudan I, J. Water Resour. Arid Environ., 3, 164-171, 2013.

Elagib, N. A. and Elhag, M. M.: Major climate indicators of ongoing drought in Sudan, J. Hydrol., 409, 612-625, 2011.

Elshamy, M. E., Seierstad, I. A., and Sorteberg, A.: Impacts of climate change on Blue Nile flows using bias-corrected GCM scenarios, Hydrol. Earth Syst. Sci., 13, 551-565, doi:10.5194/hess13-551-2009, 2009.

Enyew, B., Van Lanen, H., and Van Loon, A.: Assessment of the Impact of Climate Change on Hydrological Drought in Lake Tana Catchment, Blue Nile Basin, Ethiopia, J. Geol. Geosci., 3, p. 174, 2014.

Erwin, K. L.: Wetlands and global climate change: the role of wetland restoration in a changing world, Wetl. Ecol. Manag., 17, 71-84, 2009.

Ficklin, D. L., Luo, Y., Luedeling, E., Gatzke, S. E., and Zhang, M.: Sensitivity of agricultural runoff loads to rising levels of $\mathrm{CO}_{2}$ and climate change in the San Joaquin Valley watershed of California, Environ. Pollut., 158, 223-234, 2010.

Finlayson, C., Gitay, H., Bellio, M., van Dam, R., and Taylor, I.: Climate variability and change and other pressures on wetlands and waterbirds: impacts and adaptation, Waterbirds Around the World, edited by: Boere, G. C., Galbraith, C. A., and Stroud, D. A., The Stationery Office, Edinburgh, 88-97, 2006.

Fowler, H., Blenkinsop, S., and Tebaldi, C.: Linking climate change modelling to impacts studies: recent advances in downscaling techniques for hydrological modelling, Int. J. Climatol., 27, 1547-1578, 2007.

Gebre, S., Tadele, K., and Mariam, B.: Potential Impacts of Climate Change on the Hydrology and Water resources Availability 
of Didessa Catchment, Blue Nile River Basin, Ethiopia, J. Geol. Geosci., 4, p. 193, doi:10.4172/2329-6755.1000193, 2015.

Gitay, H., Suárez, A., Watson, R. T., and Dokken, D. J.: Climate change and biodiversity, Intergovernmental Panel on Climate Change, Geneva, 2002.

Gorham, E.: Northern peatlands: role in the carbon cycle and probable responses to climatic warming, Ecol. Appl., 1, 182-195, 1991.

Hakim, S., Fadlalla, B., Awad, N. M., and Wahab, S. A.: Ecosystems of the vegetation of Dinder national park. Unpublished report, Wildlife Research Unit, Khartoum, Sudan, 1978.

Hay, L. E., Wilby, R. L., and Leavesley, G. H.: A comparison of delta change and downscaled GCM scenarios for three mounfainous basins in THE UNITED STATES1, JAWRA Journal of the American Water Resources Association, 36, 387-397, 2000.

Jury, M. R.: Statistical evaluation of CMIP5 climate change model simulations for the Ethiopian highlands, Int. J. Climatol., 35, $37-$ 44, 2015.

Kallis, G.: Droughts, Annu. Rev. Env. Resour., 33, 85-118, 2008.

Keddy, P.: Wetland Ecology: Principles and Conservation, 2000, Cambridge, UK: Cambridge University Press, 2000.

Mantyka-pringle, C. S., Martin, T. G., and Rhodes, J. R.: Interactions between climate and habitat loss effects on biodiversity: a systematic review and meta-analysis, Glob. Change Biol., 18, 1239-1252, 2012.

Masih, I., Maskey, S., Mussá, F. E. F., and Trambauer, P.: A review of droughts on the African continent: a geospatial and long-term perspective, Hydrol. Earth Syst. Sci., 18, 3635-3649, doi:10.5194/hess-18-3635-2014, 2014.

Mattsson, J. O. and Rapp, A.: The recent droughts in western Ethiopia and Sudan in a climatic context, Ambio, 20, 172-175, 1991.

McKee, T. B., Doesken, N. J., and Kleist, J.: The relationship of drought frequency and duration to time scales, Proceedings of the 8th Conference on Applied Climatology, 179-183, 1993.

Millennium Ecosystem Assessment: Ecosystems and human wellbeing: biodiversity synthesis, Island Press Washington, DC, 2005.

Mishra, A. K. and Singh, V. P.: A review of drought concepts, J. Hydrol., 391, 202-216, 2010.

Neitsch, S., Arnold, J., Kiniry, J., Srinivasan, R., and Williams, J.: Soil and Water Assessment Tool User's Manual: Version 2000. GSWRL Report 02-02, BRC Report 02-06, Publ. Texas Water Resources Institute, TR-192, College Station, Texas, 2002.

Neitsch, S., Arnold, J., Kiniry, J., Srinivasan, R., and Williams, J.: Soil and water assessment tool input/output file documentation, Blackland Research Center, Temple, Texas, 2005a.

Neitsch, S., Arnold, J., Kiniry, J., Williams, J., and King, K.: Soil and water assessment tool theoretical documentation. Grassland, Soil and Water Research Laboratory, Temple, TX, $2005 \mathrm{~b}$.

Poff, N. L. and Ward, J. V.: Implications of streamflow variability and predictability for lotic community structure: a regional analysis of streamflow patterns, Can. J. Fish. Aquat. Sci., 46, 18051818, 1989.

Poff, N. L. and Zimmerman, J. K.: Ecological responses to altered flow regimes: a literature review to inform the science and management of environmental flows, Freshwater Biol., 55, 194-205, 2010.
Sennikovs, J. and Bethers, U.: Statistical downscaling method of regional climate model results for hydrological modelling, Proc. 18 th World IMACS/MODSIM Congress, Cairns, Australia, 2009.

Setegn, S. G., Rayner, D., Melesse, A. M., Dargahi, B., and Srinivasan, R.: Impact of climate change on the hydroclimatology of Lake Tana Basin, Ethiopia, Water Resour. Res., 47, W04511, doi:10.1029/2010WR009248, 2011.

Steele-Dunne, S., Lynch, P., McGrath, R., Semmler, T., Wang, S., Hanafin, J., and Nolan, P.: The impacts of climate change on hydrology in Ireland, J. Hydrol., 356, 28-45, 2008.

Svoboda, M., Hayes, M., and Wood, D.: Standardized precipitation index user guide, World Meteorological Organization Geneva, Switzerland, 2012.

Tavakoli, M. and De Smedt, F.: Impact of climate change on streamflow and soil moisture in the Vermilion Basin, Illinois, J. Hydrol. Eng., 17, 1059-1070, doi:10.1061/(ASCE)HE.19435584.0000546, 2011.

Taye, M. T. and Willems, P.: Influence of downscaling methods in projecting climate change impact on hydrological extremes of upper Blue Nile basin, Hydrol. Earth Syst. Sci. Discuss., 10, 7857-7896, doi:10.5194/hessd-10-7857-2013, 2013.

Taye, M. T., Ntegeka, V., Ogiramoi, N. P., and Willems, P.: Assessment of climate change impact on hydrological extremes in two source regions of the Nile River Basin, Hydrol. Earth Syst. Sci., 15, 209-222, doi:10.5194/hess-15-209-2011, 2011.

Teutschbein, C. and Seibert, J.: Bias correction of regional climate model simulations for hydrological climate-change impact studies: Review and evaluation of different methods, J. Hydrol., 456, 12-29, 2012.

Thom, H. C.: A note on the gamma distribution, Mon. Weather Rev., 86, 117-122, 1958.

Thomas, C. D., Cameron, A., Green, R. E., Bakkenes, M., Beaumont, L. J., Collingham, Y. C., Erasmus, B. F., De Siqueira, M. F., Grainger, A., and Hannah, L.: Extinction risk from climate change, Nature, 427, 145-148, 2004.

UNESCO: Water Development Report for Ethiopia, Water Development Report for Ethiopia. UN-WATER/ WWAP/2006/7, World Water Assessment Program Report, MOWR, Addis Ababa, Ethiopia, 2004.

Whiteman, A.: The Geology of the Sudan Republic, Clarendon Press, Oxford University Press, London, 1971.

Wigley, T. and Jones, P.: England and Wales precipitation: a discussion of recent changes in variability and an update to 1985 , J. Climatol., 7, 1-246, 1987.

Wilby, R. L., Dawson, C. W., and Barrow, E. M.: SDSM - a decision support tool for the assessment of regional climate change impacts, Environ. Model. Softw., 17, 145-157, 2002.

Willems, P., Olsson, J., Arnbjerg-Nielsen, K., Beecham, S., Pathirana, A., Gregersen, I. B., Madsen, H., and Nguyen, V.: Impacts of Climate Change on Rainfall Extremes and Urban Drainage Systems, IWA Publishing Company, 2012.

Woo, M.-K., Rowsell, R. D., and Clark, R. G.: Hydrological classification of Canadian prairie wetlands and prediction of wetland inundation in response to climatic variability, 79, Canadian Wildlife Service Saskatoon, Canada, 1993.

Wu, X., Liang, X. Z., and Zhang, G. J.: Seasonal migration of ITCZ precipitation across the equator: Why can't GCMs simulate it?, Geophys. Res. Lett., 30, 1824-1827, doi:10.1029/2003GL017198, 2003. 
Xu, C.-Y.: Climate change and hydrologic models: A review of existing gaps and recent research developments, Water Resour. Manag., 13, 369-382, 1999. 